ANL/CTR-75-1

Controlled Thermonuclear Processes and Plasma Physics (UC-20)

\author{
ARGONNE NATIONAL LABORATORY \\ 9700 South Cass Avenue \\ Argonne, Illinois 60439
}

\title{
A TECHNICAL CRITIQUE ON \\ RADIATION TEST FACILITIES FOR THE \\ CTR SURFACE AND MATERIALS PROGRAM
}

by

P. J. Persiani

Applied Physics Division

This report was prejured as an account of work spinsored by the United States Government. Neither the United States nor the United States Energy Research and Development Administration, nor any of their employees, nor any of their contractors, subcontractors, or their employees, makes any warranty, express or implied, or assumes any legal liability or responsibility for the accuracy, completeness or usefulness of any information, apparatus, product or process disclosed, or represents that its use would not infringe privately owned rights.

February 1975 
TABLE OF CONTEITS

No.

Title

Page

ABSTRACT. . . . . . . . . . . . . . . . . . 5

I. INTRODUCTION. . . . . . . . . . . . . . 6

A. Surface Radiation Effects. . . . . ..... 6

B. Bulk Radiation Effects .............. 7

C. Technical Justification for Radiation Facilities . . 7

II. RADIATION TEST FACILITY . . . . . . . . . . . . . 18

A. Neutron Source ................ 18

A. 1. Rotating Target Neutron Source (LLL) . . . . 18

a. Target Design and Flux Limits. . . . . 20

b. The Utility of RT-II in Surface and Bulk Radiation Program. . . . . . . . . 21

c. Accessibility Limits . . . . . . . 23

d. Remarks................ 23

A.2. Intense $14 \mathrm{MeV}$ Neutron Source (INS)

Facility (LASL). . . . . . . . . . . 24

a. Beam Transport and Multistage Differential Pumping. ............ 24

b. Source Accessibility . . . . . . . . 27

c. Aerodynamics of Supersonic Jet-Flow. . . . 27

d. Surface and Bulk Radjation Studies . . . 28

e. Remarks. . . . . . . . . . . . . 29

B. Plasma Source. . . . . . . . . . . . 30

B. 1 Dense Plasma Focus (CPF) ......... 30

a. Neutron Scaling. ........... . 32

b. DPF Device as a Plasma Source. . . . . 33

c. Deuterium-Tritium Gas. . . . . . . 37

d. Pulsed Energy Storage and Transfer System. 37

e. Potential Utility of a DPFRTF. . . . . 38

f. Accessibility. ........... 40

g. Upgrading Options for the Radiation

Facility................. 42

h. Pulsing us. Steady State Testing. ... . 44

B.2. Other Plasma Devices........... 44

III. SUMMARY STATEMENT ON THE TEST FACILITIES. . . . . . . 46

IV. RECOMMENDATIONS . . . . . . . . . . . . . . 48

A. Surface Radiation Studies... . . . . . . . . . 48

B. Bulk Radiation Studies. . . . . . . . . . . 50

C. Pemarks on Facility Design. . . . . . . . . . . . 51

REFERENCES . . . . . . . . . . . . . . . . . . . 55 


\section{LIST OF FIGURES}

No.

Title

Page

1. Neutron yields $N$ vs energy E, assembled by H. Rapp (Ref. 22) . . . . . 34

2. Peak Neutron yield vs Capacitor Bank Energy . . . . . . . . . . . . . 35

3. CTR Neutron and Plasma Source Concepts and Related Devices Development . 41

\section{LIST OF TABLES}

No.

Title

Page

I. Neutron and Plasma Source Requirements - Surface Radiation

Effect Expeniments ........................... 8

II. Surface Radiation Studies . . . . . . . . . . . . . . . . 10

III: Neutron and Plasma Source Requirements - Bulk Radiation Effect Experiments 12

IV. Máterial Radiation Studies ...................... 16

V. Summary: Rotating Target $14 \mathrm{MeV}$ Neutron Source Facility (RTNS, LLL) . . 19

VI. Summary: Intense $14 \mathrm{MeV}$ Neutron Source Facility (INS, LASL) . . . . . . 25

VII. Summary: Dense Plasma Focus (DPF, LASL) . . . . . . . . . . . . . . . 39

VIII. Surface Science Program and Radiation Test Facilities . . . . . . . . . 43

IX. Composite Summary of Parameters of Neutron and Plasma Sources . . . . . 47 


\title{
A Technical Critique on Radiation Test Facilities for the CTR Surface and Materials Program*
}

\author{
P. J. Persiani
}

\begin{abstract}
Majcr radiation test facilities will be necessary in the near-term ( 5 years) and long-term ( $>10$ years) future for the timely developmer.t and understanding of fusion confinement systems and of prototype fusion power reactors. The study includes the technical justifications and requirements for CTR Neutron and Plasma Radiation Test Facilities. The initial technical critique covers the feasibility and design problems: in upgrading the performance of the acceleratorrotating (solid $\mathrm{T} i \mathrm{~T}$ ) target systems, and in transforming the accelerator-supersonic jet target concept into a radiation testing facility. A scoping assessment on the potential of a pulsed high-beta plasma device (dense plasma focus) is introduced to explore plasma concepts as nearterm neutron and plasma radiation sources for the CTR S!!rface and Materials Program.
\end{abstract}

*Work performed under the auspices of the U.S. Energy Research ard Deveiopment Adoministration. 


\section{INTRODUCTION}

In assessing the technical justification and requirements for a CTR Radiation (plasma and neutron) Test Facility, it is necessary to delineate the CTR Materials Program into two general areas of study: (A) Surface Radiation Effects and (B) Bulk Radiation Effects.

\section{A. Surface Radiation Effects}

The surface radiation effects involves the study of the primary and secondary plasma radiation (MeV neutrons, energetic particles and ions, $X$ rays, brensstrahlung, suft $x$-rays and synchrotron radiation) interaction effects on the immediately adjacent wall materials. The resulting blistering, sputtering, and particle emission lead to wall erosion and plasma contamination, which in turn influences the physics of plasma confinement and heating. A most important aspect of the overall surface area problem is that the incident radiation field is a spectrum of reaction meciranisms. The surface problem relates directly to the plasma physics and confinement experiments currently being carried out in the major CTR laboratories. The importance of these experiments, which are aimed at demonstrating the scientific feasibility of confining thermonuclear plasmas, places a priority of elforts in this phase of the national Controlled Thermonuclear Research Program.

The more long range consequences of plasma-wall interactions will eventually include effects on the physical a:l structural integrity of surface components relating to the conditions in fusicn power reactors. 


\section{B. Bulk Radiation Effects}

The bulk radiation effects involves the study of fusion spectra (eV to 14 ieV) neutrons with the structural component materials of high powered fusion reactors. The volume integrated (bulk) neutron fluence effects on the physical and mechanical properties, creep strength, ductility and dimensional instability (swelling) relate to the design problems of the more long-range development of prototype and/or demonstration fusion Dower reactors. However, the high performance conditions associated with the power reactors necessitates the early study of materials under intense neutron radiation conditions. The study of these problems is a major phase of the national CTR materials program.

\section{Technical Justification for Radiation Facilities}

The national CTR surface science and culk radiation experimental program needs forms a basis for developing an advanced radiation test capability.

The recent advances made in surface physics by the investigators at several laboratories has placed a timely priority in this area of study. The planned experimental program has been extended to study surface effects which require diverse radiation sijurces and at intensity levels higher than those currently available. The investigations include the study of the separate surface efferts from MeV neutron sources, particle accelerators, photon sources, and in various combinations in order to assess the change in surface effects by the mutual interaction of the radiation fields.

Measurements descriptiors for surface effects experiments and facility requirements are summarized in Table I [Ref 1, developed in collaboration with M. Kaminsky (ANL); F. CT inärd (LASL); R. Werner et al (LLL); W. Bauer (Sandia); 0. Harling (PNL)] and in Table II. The program emphasizes the need for studying the simultaneous impact of radiation on surface materials. 
TABLE I, Neutrorl and Plasma Surrez Requirements

Surface Radiation Effects Experiments

Measuremencs Description

\section{1. (ANL)}

Surface Radiation Riffects Neutron Impact Studies on surfaces of matexials, surface erosion and release of particulate mat ter.

2. (ANL)

Simultaneous Impact Studies of energetic photo:s and neutrons on surfaces of materials, surface erosion and release of particulate matter.

\section{3. (ANL)}

Simultaneous Impact

Studies of Energetic

particles, photons.

and neutron's on the

surface of materials,

surface erosicn and

release of particulate

inatter.

\section{4. (LASL)}

Surface and Surface Related Experiments Study of electrical insulator properties under cyclic thermal stress conditions. Radiation enhaxced chemical reaction between insulator and metal backing, diffusion, swetling effects of metal-insulator

interface, corrosion at

metal-lithium interface.

Electrical Resistance of

compression cull in
Energy

Distribution

Source Geometry

Operational Mode

Physical Jescription of Experiwental Apparatus and Facility Access
Neutron Flux
$5 \times 10^{10}$ to $5 \times 10^{14}$

$\mathrm{n} / \mathrm{cm}^{2}-\mathrm{sec}$
Neutron Fluence

Neutron Fluence
$10^{17}$ to $10^{22} \mathrm{n} / \mathrm{cm}^{2}$
Discrete Energies Beam Flux or $>0.1$ to $: 4 \mathrm{MeV}$ Point Source neutrons, and

Fusion Spectrum.
Continuous and/or Pulsed Operation

Neutron Flux
$5 \times 10^{10}$ to $5 \times 1014$
$n / \mathrm{cm}^{2}$ sec
Neutron Fluence
$10^{17}$ to $10^{22} \mathrm{n} / \mathrm{cm}^{2}$
iuton $\mathrm{bi}: 1 \mathrm{x}$
$>10^{10} / \mathrm{cm}^{2}-\mathrm{sec}$

$>10^{10} / \mathrm{cm}^{2}-\mathrm{sec}$

\section{Neutron Flux}

$5 \times 10^{10}$ to $5 \times 10^{14}$

$\mathrm{n} / \mathrm{cm}^{2}-\mathrm{sec}$

Neut ron Fluence

$10^{17}$ to $10^{22} \mathrm{n} / \mathrm{cm}^{2}$

$>1010$ Flux

Particle (D,T

and $4_{\mathrm{He}}$ ) Flux

$1 \times 10^{10}$ to $4 \times 10^{14}$

ions $/ \mathrm{cm}^{2}-\mathrm{sec}$

\section{Neutron $\mathrm{F} ! \mathrm{ux}$ up
to 10
$\mathrm{n} / \mathrm{cm}^{2}-\mathrm{sec}$}

Neutron Fluence
up to $3 \times 10^{22} \mathrm{n} / \mathrm{cm}^{2}$

up to $3 \times 10^{22} \mathrm{n} / \mathrm{cm}^{2}$
lntensity of Par-

ticles and photons

consistent with

neutron fluence
Discrete Energies Beam Flux or

$>0.1$ to $14 \mathrm{MeV}$

neutrons, and

Fusion Spectrum.

Pheter. energy

range 0.1 to

$100 \mathrm{keV}$ and

Fusion Spectrum

Discrete Energies Beam Fiux or

$>0.1$ to $14 \mathrm{MeV}$ Polnt surc.

neutrons, and

Fusion Spectrum.

Photon energy

range 0.1 to 100

kel and Fusion

Spectrum

Particle energy

range $\mathrm{D}^{+} \mathrm{T}^{+} 5-25$

keV, $\mathrm{He}^{+}$50-500

keV and Fusion
Spectrum of Photons

Fusion Reactor

Spectrum Neutron

and Particliss
Beam Flux and

in sicu Capability
Pulsed Operation

$100 \mathrm{msec}, 0.333$

to 0.1 pps
Electrical and thermel Conductivities Test Size 0.5 to $2 \mathrm{~cm}$ dia. Density Teat Sizes -1 cin. Mechanical Testing $-1-5 \mathrm{im}$
Test specimen size -1 to $5 \mathrm{~cm}$ dia. Space requirements of supporting apparatus $1 \mathrm{~m}$ length, $1 \mathrm{~m}$ width, 2m height.

Test specimen $\sim 1$ to $5 \mathrm{~cm} \mathrm{dia.} \mathrm{Space}$ requirements of supporting apparatus 2 on length, $1 \mathrm{~m}$ width and $2 \mathrm{~m}$ height.

Test specimen size $\rightarrow$ to 5 cin dia. Space requirements of supporting apparatus $2 \mathrm{~m}$ length, $3 \mathrm{~m}$ width and 3 m height. 


\section{Measurements Description}

5. (LASL)

To study prototype in-

sulator/metal first wall

sections to environment

of a pulsed fusion reactor

6. (LLL)

Surface Experiments

2. Sinultio " and He erosion effects.

b. Simultaneous neutral and neutron effects.

c. $14 \mathrm{MeV}$ neutron sputtering.

\section{7. (Sandia Livermore)}

Surface Experiments

Plasma Source

a. $14 \mathrm{MeV}$ Neutron Sputtering at different Lemperatures.

b. He and/or $H$ isotcpe

irradiation of samples exposed to high fluences of $14 \mathrm{MeV}$ neutrons.

c. Simultaneous He and/or $H$ isotope irradiation at different zemperatures for surface ezosion and particle remission.

d. Combined plasma radtation fields.

8. (PNL)

Investigation of Surtace effects. (1) Sputtering as a function of parsm. eters suct as: materials, eters suck as: materials, metallurglcal condictor (including radiation
damage condition), temperature, surface condition and neut ron energy. (2) Deter. mination of ratiolsotopic content of materials removed from the vacuum wall by neutron bombardment.

(3) Comblned effects of neutron, ions, $x$-rays. electrons, photons and chemical corrosion an surfaces uf C:TR materials. vithe ter nat: :

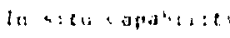
flux $-10^{17} \mathrm{n} / \mathrm{cm}^{2}-\mathrm{sec}$ partisleant

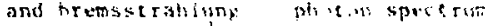
eneryy -io ilsme

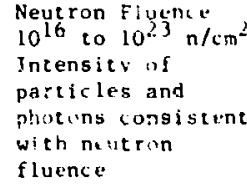

with neitron

fluence

Discrete !h

MeV and

Fusion spe:cer.tm

Neutron Flux

$10^{13}-10^{15} \mathrm{n} / \mathrm{cm}^{2}-\mathrm{sec}$

Neutron iluence

$-10^{22} \mathrm{n} / \mathrm{cm}^{2}$

Fluence $19 \mathrm{p} / \mathrm{cm}^{2}$ liven Flux

and if situ

rapahilit.
Partioles
Instantancous Neutron fusion Siest $:$.

Particle flux $10^{10}$ to $10^{17} \mathrm{p} / \mathrm{cm}^{2}-\mathrm{sec}$

i $2-3 \times 10^{20} \mathrm{p} / \mathrm{cm}^{2}$

$\begin{array}{lll}\text { Neutron Fluk } & \text { Discrete le } & \text { Beam flux and } \\ 10^{12} \text { to }>10 & \text { MeV } & \text { In situ flux } \\ \mathrm{n} / \mathrm{cm}^{2}-\mathrm{sec} & \text { and Fusion } & \end{array}$

$\mathrm{n} / \mathrm{cm}^{2}-\mathrm{sec}$

Neutron Fluence
$10^{17}$ to $10^{22} \mathrm{n} / \mathrm{cm}^{2}$ aratina: ?ede

abed uperation vis mes, 0.333

$\therefore$ 13. I pps

(i)ntinusus opera.

tion
Cint inumus 17ward-

$\operatorname{tin}$

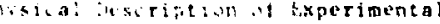
Aportalus and Facillex Access

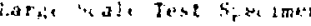

Whater of Experaments - 20

Sitmere if tepotriments - io

Number of Experiments . 20

rest specinen size $1-40 \mathrm{~cm} \mathrm{dia.}$ Vacuum sistems $10^{-6}$ to $10^{-8}$ for In situ access spoce to accommodate: mass spectrineter. electron spectrometer, K-rav deteres, sputered dew colledtor four tubes having dinension $20 \mathrm{~cm}$ dia., to cm length.
Acress zavity: - 30 liters in high flux region: $\sim$ ho liters in lower radiation fields Access area tur inst rument ation' a ads, vacution svstems, etc.
Intensity of Particles and photions consiscent with atrove went ron flux
Cont inunes Ireadiatiun, Koom Temperature low haikground rabiation in cavit fur easy setup of experiments. Ruvm Temputrature 
A. Measurement Description

1. Vacuum wall, surface components, and insulators erosion

a. Sputtering.

b. Radiation blistering by photons, particles, neutron and reaction products: $(n, \alpha),(n, p)$, etc.

c. Particle desorption by direct plasma radiation, neutron and reaction produc : interactions.

d. Photo-decomposition of surface compounds by plasma and by neutrcninduced energetic photons and reaction products.

e. Radiation damage in surface layers.

2. Plasma contamination

a. Multiple backscattering.

b. Secondary particle emission (see 1.a-1.d abnve).

c. Secondary electron emission (electron sheath formation).

B. Source Description

Plasma Density:

Neutron Energy Range:

Intensity (at sample surface):

Fluence (yield 0.1 monolayer):

High Fluence Effects:

Geometry:
$10^{16} \mathrm{p} / \mathrm{cm}^{3}$

$\mathrm{keV}-14 \mathrm{MeV}$

$>10^{12} \mathrm{n} / \mathrm{cm}^{2}-\mathrm{sec}$

$3 \times 10^{17} \mathrm{n} / \mathrm{cm}^{2}$

$10^{20}-10^{21} \mathrm{n} / \mathrm{cm}^{2}$

point source, beam flux 
This emphasis is consistent with the increasing preoccupation of the plasma physicists in the confinement program on the effects of wall impurities and plasma contamination in the present generation of plasma physics experiments (Ref. 2-12). The concern with the plasma contamination problems extends to the next generation of confinement experiments including the $(D, T)$ burner Fusion Test Reactors such as the Tokamak Fusion Test Reactor (TFTR).

These experimental systems involye the synergetic effects of the plasma radiation component processes on the surface walls. The surface group proposes to study these integral effects with a source simulating as closely as possible a thermonuclear plasma.

The proposed oulk radiation experiments are summarized in Table III (Ref. 13 developed in collaboration with F. W. Wiffen, J. Stiegler, E. E. Bloonii and J. H. LeVan (ORNL); W. V. Green (LASL); R. Werner, (LLL); T. T. Claudson, and H. Yoshikawa (HEDL); H. Wiedersich, and B. R. T. Frost (ANL); R. D. Marshall, R. E. Westerman, J. L. Brimhall, and W. C. Morgan (PNL)) and the measurement description with neutron source strength requirements are included in Table IV. The test conditions for the bulk studies require neutron fluxes and fluences of one or two orders of magnitude greater than the needs specified in the surface science program. The minimum fluence needed to obtain observable measurements for surface effects $\left(210^{17}\right.$ to $\left.10^{18} \mathrm{n} / \mathrm{cm}^{2}\right)$ is lower than the minimum fluence requirements for measuring observable bulk effects $\left(>10^{20} \mathrm{n} / \mathrm{cm}^{2}\right)$.

Neutron source facilities in the energy range and intensities of longterm interest to the CTR program are presently not available. However, there are some basic materials studies (neutron and ion-bombardment correlation experiments, void formation, defect formation, etc.) which may be satisfied with the neutron fiux levels in the upper range required by the surface program. 
TABLE III. Neutron and Plasma Source Requiremente

Bulk Radiation Effects Experiments

\begin{tabular}{l} 
Measurements Description \\
\hline 1. (ORNi) \\
Bulk Radiation Correlation \\
of Neutron Energy Effects \\
to correlate damage pro- \\
duced in test facility to \\
other facilities in CTR \\
materials program. Pro- \\
vide critical test of the- \\
ories and models used to \\
extrapolate fission reac- \\
tor dmage to anticipate \\
CrR spectrum effects. \\
Study to be made for CTR \\
materials.
\end{tabular}

Energy

Radiation Field

Distribution

Source Geometry

Operational Mode Physical Description of Experimental
Apparatus and Fecility Accese

Neutron Fluence 2 Fusion Reactor Spectrun
Continuous Operation Temperatures 400 $600,800^{\circ} \mathrm{C}$

\section{2. (ORNL)}

Bulk radiation swelling studies of structural materials.

\section{3. (ORNL)}

To investigate neutron Irradiation effects on postirradiation mechan cal properties of struc. tural materials. Tensile and creep tests.

\section{4. (ORNL)}

Determine the radiationcontrolled creep rates in structural materials as a function of neutron flux and temperatures.

\section{5. (ORNL)}

To study the effect of neutron irradiation on the interaction of lithium with oxygen contained in wb- $1 \% \mathrm{Zr}$.

Test modules to occupy $\sim 50 \mathrm{~cm}^{3}$ volume. Two rodules including furneces for heating.

\section{Neutron Flux \\ $>3 \times 10^{14} \mathrm{n} / \mathrm{cm}^{2}-\mathrm{sec}$ \\ Fusion Reactor Spectrum}

$10^{22}$ to $10^{23} \mathrm{n} / \mathrm{cm}^{2}$

In situ Capability $50 \%$ uniformity of flux

\section{Neutron Flux}

$>3 \times 10^{14} \mathrm{n} / \mathrm{cm}^{2}-8 e c$

Fusion Reactor

Spectrum

In situ Capability
Continuous and pulsed operation. Temperature 300 to $1200^{\circ} \mathrm{C}$. Change-out frequency 0 to 2 per year

Continuous Operation Temperatures 300 to
$1200^{\circ} \mathrm{C}$. Change-out frequency 1 to 2 per year

\section{Neutron Flux $\sim 10^{14} \mathrm{n} / \mathrm{cm}^{2}-\mathrm{sec}$ \\ Fusion Reactor Spectrum} Neutron Fluence
$10^{20}$ to $10^{22} \mathrm{n} / \mathrm{cm}^{2}$

In situ Capability $10 \%$ uniformity of of flux over $5 \mathrm{~cm}$ length

Cont Inuou: Operation Tewperature range 300 to $800^{\circ} \mathrm{C}$.

Change-out frequency

2 to 20 per year

Continuous Operaction Test capsule $\sim 1.0 \mathrm{~cm}$ die by $3 \mathrm{~cm}$ Neutron Flux Discrete $14 \mathrm{MeV}$ Beam Flux $10^{14}$ to $10^{15} \mathrm{n} / \mathrm{cm}^{2}$ - Spectrum sec
Test volume of one module $10 \mathrm{~cm}$ by $10 \mathrm{~cm}$ by $20 \mathrm{~cm}$ including rurnaces.
Test volume $5 \mathrm{~cm}$ dieneter $30 \mathrm{~cm}$ length for in-reactor creep aodule. 
TABLE 111. (Contd.)

\begin{tabular}{|c|c|c|c|c|c|}
\hline Measurements Description & Radiation Field & $\begin{array}{l}\text { Energy } \\
\text { Distribution }\end{array}$ & Source Geometry & Operational Made & $\begin{array}{l}\text { Physical Description of Experimental } \\
\text { Apparatus and Facility Access }\end{array}$ \\
\hline 6. (ORNL) & & & & & \\
\hline $\begin{array}{l}\text { To study effects of neutron } \\
\text { flux on dissolution and } \\
\text { deposition kinetics for } \\
\text { stainless steels and re- } \\
\text { fractory metals in liquid } \\
\text { lithium. } \\
\text { 7. (LASL) }\end{array}$ & $\begin{array}{l}\text { Neutron Flux } \\
10^{14} \text { to } 10^{15} \mathrm{n} / \mathrm{cm}^{2}- \\
\text { sec }\end{array}$ & $\begin{array}{l}\text { Discrete } 14 \mathrm{MeV} \\
\text { Spectrum }\end{array}$ & Beam Flux & Continuous Operation & $\begin{array}{l}\text { Test capsule } \sim 1.0 \text { dia by } 3 \mathrm{~cm} \text { high } \\
\text { with } \sim \frac{1}{2} \text { capsule volume in beam. }\end{array}$ \\
\hline $\begin{array}{l}\text { Bulk Radiation Experiments } \\
\text { Radiatiun effects on carbon } \\
\text { and beryllium. Material } \\
\text { strength of structural } \\
\text { components, and super- } \\
\text { conducting properties. } \\
\text { 8. (LASL) }\end{array}$ & $\begin{array}{l}\text { Neutron Flux } \\
\text { up to } 10^{15} \mathrm{n} / \mathrm{cm}^{2}-\mathrm{sec} \\
\text { Neutron } F 1 \mathrm{uence} \\
\text { up to } 3 \times 10^{22} \mathrm{n} / \mathrm{cm}^{2}\end{array}$ & $\begin{array}{l}\text { Discrete } 14 \mathrm{MeV} \\
\text { and Fusion } \\
\text { Spectrum }\end{array}$ & $\begin{array}{l}\text { Beam Flux and } \\
\text { in situ Capalifity }\end{array}$ & $\begin{array}{l}\text { Pulsed Operation } \\
100 \mathrm{msec}, 0.333 \\
\text { to } 0.1 \mathrm{pps} \text { and } \\
\text { continuous operation }\end{array}$ & $\begin{array}{l}\text { Bulk properties: Test size } \sim 1 \mathrm{~cm} \\
\text { Themal Conductivities Test size } 0.5 \\
\text { to } 1 \mathrm{~cm} \text { die. Density Test sizes } \sim 1 \\
\mathrm{~cm} \text {. Mechanical Testing } \sim 1-5 \mathrm{~cm} \text {. }\end{array}$ \\
\hline $\begin{array}{l}\text { Electrical Insulator Experi- } \\
\text { ments to study electrical } \\
\text { properties of insulators and } \\
\text { composite insulators/metal } \\
\text { specimens at temperatures } \\
\text { and at irradiation condi- } \\
\text { tions of the pulsed theta- } \\
\text { pinch reactor. Messurements } \\
\text { on pulsed and DC dielectric } \\
\text { strength and resistivity. } \\
\text { 9. (LASL) }\end{array}$ & $\begin{array}{l}\text { Ins tantaneous } \\
\text { Neut ron Flux } \\
\sim 10^{17} \mathrm{n} / \mathrm{cm}^{2}-\text { sec }\end{array}$ & $\begin{array}{l}\text { Fusion Neutron, } \\
\text { Particle, and } \\
\text { Photon Spectrum }\end{array}$ & In situ Capability & $\begin{array}{l}\text { Pulsed Operation } \\
100 \text { msec, } 0.333 \text { to } \\
0.1 \text { pps. Rapld } \\
\text { withdrawal of rest } \\
\text { spesimen. Tempera- } \\
\text { ture } 800^{\circ} \mathrm{C}\end{array}$ & $\begin{array}{l}\text { Test specimen sizes } 3 \mathrm{~cm} \text { dia, space } \\
\text { requirements of supporting apparatus } \\
10 \mathrm{~cm} \text { diu by } 10 \mathrm{~cm} \text { length. } 1 \times 1 \mathrm{~m} \\
\text { floor ares adjacent to test reactor. }\end{array}$ \\
\hline $\begin{array}{l}\text { To study structural prop- } \\
\text { erties of electrical insu- } \\
\text { lators and composite insu- } \\
\text { lators/metal specimena at } \\
\text { temperatures and at irradi- } \\
\text { ation condition. } \\
\text { 10. (LLL) }\end{array}$ & $\begin{array}{l}\text { Instantaneous } \\
\text { Neutron Flux } \\
\sim 10\left[7 \mathrm{n} / \mathrm{cm}^{2}-\mathrm{sec}\right. \\
\text { and related } \\
\text { energetic par- } \\
\text { ticle and photons }\end{array}$ & $\begin{array}{l}\text { Fusion Neutron, } \\
\text { Particle, and } \\
\text { Photon Spectrum }\end{array}$ & In situ Capability & $\begin{array}{l}\text { Pulsed Operation } \\
100 \text { mbec, } 0.333 \\
\text { to } 0.1 \text { pps. Post - } \\
\text { irradiation evalu- } \\
\text { ation. Tempera- } \\
\text { tures } \sim 800-1200^{\circ} \mathrm{C}\end{array}$ & $\begin{array}{l}\text { Test specimen size } 2-4 \mathrm{~cm} \text {. Space } \\
\text { requirements of supporting apparatua } \\
10 \mathrm{~cm} \text { dia by } 10 \mathrm{~cm} \text { length }\end{array}$ \\
\hline $\begin{array}{l}\text { Bulk Radiation Damage Study } \\
\text { Physical and Mechanical } \\
\text { Properties. Creep Stresa } \\
\text { as Function of Temperature. } \\
\text { No load to load for } 1 \% \\
\text { creep in } 10,000 \mathrm{hr} \text {. } \\
\text { Corrosion and Permeation } \\
\text { Studies. }\end{array}$ & $\begin{array}{l}\text { Neutron Flux } \\
10^{14} \text { to } 10^{15} \mathrm{n} / \mathrm{cm}^{2}-\text {, } \\
\text { sec } \\
\text { Neutron Fluence } \\
10^{16}=10^{23} \mathrm{n} / \mathrm{cm}^{2} \\
\text { in powers of } 10\end{array}$ & $\begin{array}{l}\text { Fusion Reactor } \\
\text { Spect rum }\end{array}$ & In situ Copability & $\begin{array}{l}\text { Cont inuous Operation } \\
\text { Room Temperature } \\
0.6 \mathrm{~T}_{\text {melt }} \text { in } 200^{\circ} \mathrm{C} \\
\text { interval. }\end{array}$ & 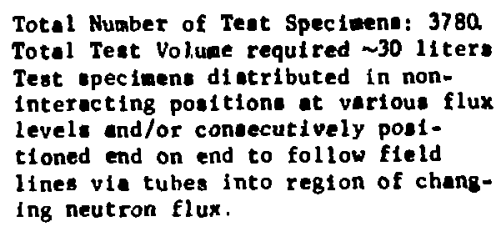 \\
\hline
\end{tabular}


TABLE III. (Contd.)

\begin{tabular}{|c|c|c|c|c|c|}
\hline Measurements Description & Radiation Field & $\begin{array}{c}\text { Energy } \\
\text { Distribution }\end{array}$ & Source Geometry & Operational Mode & $\begin{array}{l}\text { Physical Description of Experimental } \\
\text { Apperatus and Facility Access }\end{array}$ \\
\hline \multicolumn{6}{|l|}{ 11. (ANL) } \\
\hline $\begin{array}{l}\text { To investigate materials } \\
\text { properties under plasma } \\
\text { irradiation in controlied } \\
\text { environment (temperature, } \\
\text { high vacuum, pressurized } \\
\text { gas or liquid metals or } \\
\text { all). Property changes } \\
\text { such as density, electric } \\
\text { conductance, creep strength, } \\
\text { and surface erosion to be } \\
\text { measured postirradiation. }\end{array}$ & $\begin{array}{l}\text { Neutron Flux } \\
\sim 10^{15} \mathrm{n} / \mathrm{cm}^{2}-\mathrm{sec} \\
\text { and related } \\
\text { energetic par- } \\
\text { ticles and } \\
\text { photon fluxes }\end{array}$ & $\begin{array}{l}\text { Fusion Neutron } \\
\text { and Particle } \\
\text { Spectrum }\end{array}$ & $\begin{array}{l}\text { Beam Flux and } \\
\text { in situ Capability } \\
\text { Uniform Flux over } \\
\text { specimen region }\end{array}$ & $\begin{array}{l}\text { Pulsed and Contin- } \\
\text { uous Operation. } \\
\text { Temperature } 300 \text { to } \\
1200^{\circ} \mathrm{C}\end{array}$ & $\begin{array}{l}\text { Test specimen sizes }-50 \text { cc with ad- } \\
\text { ditlonal space for supporting ap- } \\
\text { paratus. }\end{array}$ \\
\hline $\begin{array}{l}\text { Investigation of materials } \\
\text { properties during plasma } \\
\text { irradiation. }\end{array}$ & $\begin{array}{l}\text { Neutron Flux } \\
\sim 10^{15} \mathrm{n} / \mathrm{cm}^{2}-\mathrm{sec} \\
\text { and related ener- } \\
\text { getic particles } \\
\text { and photon fluxes }\end{array}$ & $\begin{array}{l}\text { Fuston Neutron, } \\
\text { Particles, and } \\
\text { Photon Spectrum }\end{array}$ & $\begin{array}{l}\text { Beam Flux and } \\
\text { In situ Capability }\end{array}$ & $\begin{array}{l}\text { Pulsed and Contin- } \\
\text { uous Operation. } \\
\text { Temperature } 300 \text { to } \\
1200^{\circ} \mathrm{C}\end{array}$ & $\begin{array}{l}\text { Testing space parallel to beam } 1 \text { in } \\
\text { width, } 2 \text { a height and } 1 \text { m depth, and } \\
10 \text { to } 12 \text { cm between source and test } \\
\text { specimen. For stall test opecimen } \\
\text { beam area } 4 \text { c⿴囗十 by } 1 \text { cm. }\end{array}$ \\
\hline \multicolumn{6}{|l|}{ 13. (HEDL) } \\
\hline $\begin{array}{l}\text { Irradiation Effects on } \\
\text { Materials Swelling, } \\
\text { Physical and Mechanical } \\
\text { Properties. }\end{array}$ & $\begin{array}{l}\text { Neutron Flux } \\
7 \times 10^{15} \mathrm{n} / \mathrm{cm}^{2}-\mathrm{sec} \\
\text { Neutron Fluence } \\
10^{24} \mathrm{n} / \mathrm{cm}^{2}\end{array}$ & $\begin{array}{l}\text { Fusion Reactor } \\
\text { Spectrum }\end{array}$ & $\begin{array}{l}\text { Di stributed Flux } \\
\text { in situ Capability }\end{array}$ & $\begin{array}{l}\text { Continuous Irradia- } \\
\text { tion } 5 \text { year irradia- } \\
\text { tion Test Program } 20 \\
\text { yr. Temperature } \\
1000^{\circ} \mathrm{C}\end{array}$ & $\begin{array}{l}6 \text { Test Positions } 4 " \text { dia, } 36 " \text { length } \\
\text { high flux. Access for instrumenta- } \\
\text { tion leads, gad lines, and wave } \\
\text { guides }\end{array}$ \\
\hline \multicolumn{6}{|l|}{ 14. (HEDL) } \\
\hline $\begin{array}{l}\text { Investigate Irradiation } \\
\text { Effect on Creep and } \\
\text { Fat1gue. }\end{array}$ & $\begin{array}{l}\text { Neutron Flux } \\
5 \times 10^{15} \mathrm{n} / \mathrm{cm}^{2}-\mathrm{sec}\end{array}$ & $\begin{array}{l}\text { Fusion Reactor } \\
\text { Spectrum }\end{array}$ & $\begin{array}{l}\text { Distributed Fiux } \\
\text { in itu Capability }\end{array}$ & $\begin{array}{l}\text { Continuous Irradia- } \\
\text { tion } 1 \text { year irradia- } \\
\text { tion period, Test } \\
\text { Prograw } 20 \text { yr. } \\
\text { Temperature } 1000^{\circ} \mathrm{C}\end{array}$ & $\begin{array}{l}2 \text { Instrumented Assemblies } 4 " \text { dia. } \\
\text { Access for wave guides into core } \\
\text { region. }\end{array}$ \\
\hline \multicolumn{6}{|l|}{ 15. (PAL) } \\
\hline $\begin{array}{l}\text { Study of acco and micro } \\
\text { structural changes by } \\
\text { neutron radiation on } \\
\text { materials as a function } \\
\text { temerature, neutron flux } \\
\text { and fluence. Sinall ceals }\end{array}$ & $\begin{array}{l}\text { Neut ron Flux } \\
>10^{I S} \mathrm{n} / \mathrm{cm}^{2}-\mathrm{sec} \\
\text { Neutron Fluence } \\
\sim 10^{24} \mathrm{n} / \mathrm{cm}^{2}\end{array}$ & $\begin{array}{l}\text { Discrete } 14 \\
\text { MeV and Fusion } \\
\text { Reactor Spectrum }\end{array}$ & & $\begin{array}{l}\text { Continuous Irradia- } \\
\text { tion. Temperature } \\
500 \text { to } 1000^{\circ} \mathrm{C}\end{array}$ & $\begin{array}{l}\text { Capsule specimen alse: } 2 \mathrm{~cm} \text { cube: or } \\
\text { tube } 1 \mathrm{~cm} \text { dia, } 5 \mathrm{~cm} \text { length. Teaper - } \\
\text { ture measuring leads. Large number } \\
\text { of specimens for simitaneous ir- } \\
\text { radiation. }\end{array}$ \\
\hline
\end{tabular}




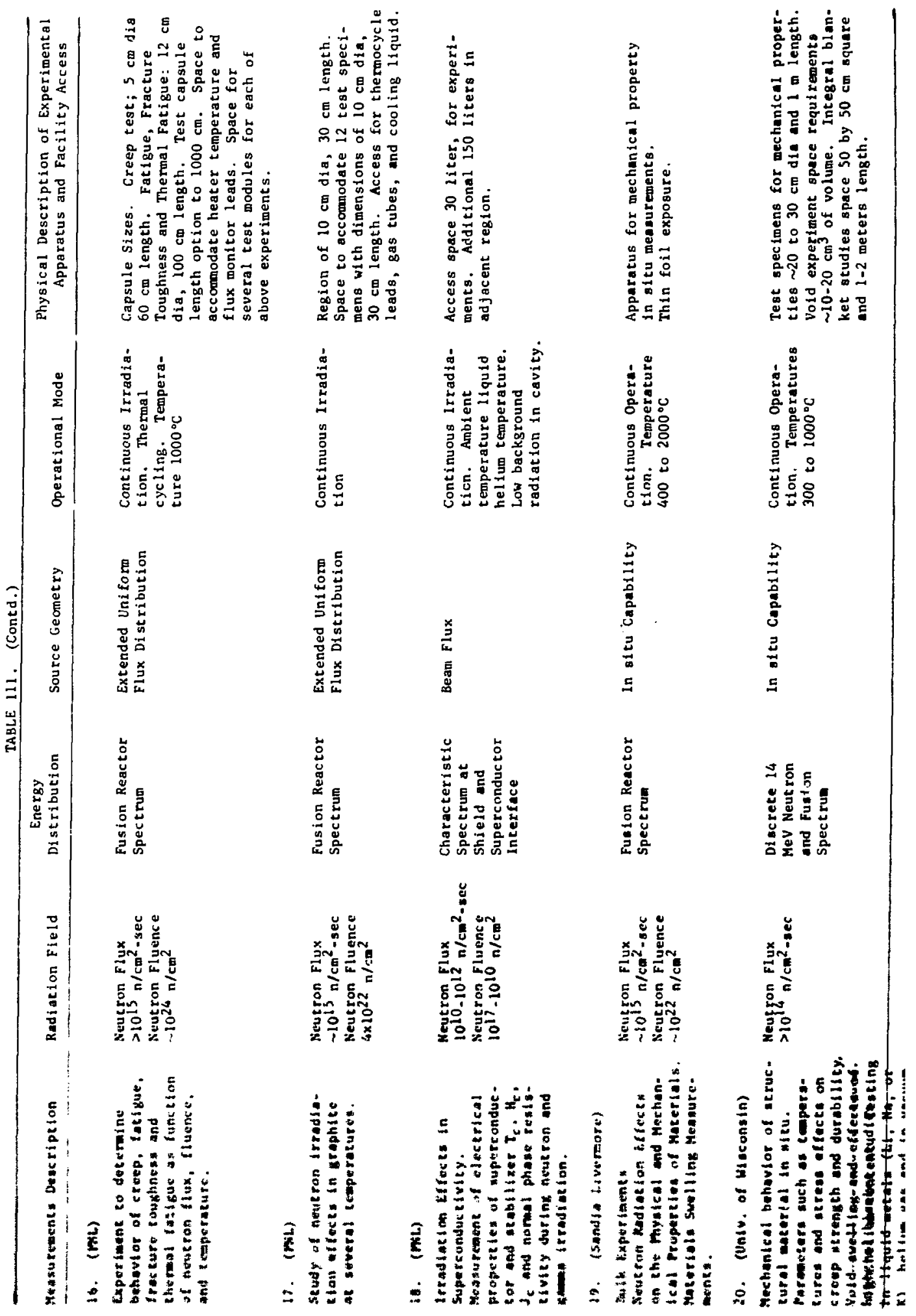


A. Measurement Description

1. Neutron fluence effects on physical and mechanical properties: creep strength, and loss of ductility in vacuum wall and structural material at temperatures in range of $500-1000^{\circ} \mathrm{C}$.

2. Synergistic effects of high gas generation and point defect production rates in a high flux of high energy neutrons on void formation at temperatures in the range of $500-1000^{\circ} \mathrm{C}$.

3. Establish correlation between heavy-ion bombardment effects and neutron radiation effects at several energies (discrete or integral) in the range of 2-14 $\mathrm{MeV}$.

4. Transmutation effects on physical and mechanical properties of structural materials.

B. Source Description

Energy Range:

Intensity (long term):

High Fluence:

Intensity (correlation experiments):

Minimum Fluence:

(irradiation period 4 mo., 2 wk.) Geometry:
keV. $14 \mathrm{MeV}$

$>10^{14} \mathrm{n} / \mathrm{cm}^{2}-\mathrm{sec}$

$10^{22}-10^{24} \mathrm{n} / \mathrm{cm}^{2}$

$10^{13}-10^{14} \mathrm{n} / \mathrm{cm}^{2}-\mathrm{sec}$

$10^{20} \mathrm{n} / \mathrm{cm}^{2}$

point source, beam flux

in-core irradiation 
The technical and non-technical justification for Radiation Test Facilities in the CTR program is based on the following considerations:

(1) The Surface Radiation Program (Table VIII, Ref. 14) has the potential for making major contributions to the near-term ( 1980$)$ critical plasma physics and confinement experiments;

(2) The surface science program has the potential for making major contributions to the Experimental Power Reactor (EFR) and Fusion Engineering Research Facility (FERF) projects;

(3) The surface science program requires that an advanced level of progress be maintained in order to better provide technical guidance and influence the overall national CTR program in understanding surface phenomena;

(4) The need to maintain, supplement, and expand on the basic bulk radiation damage study programs;

(5) The need to initate and expand on large scale bulk radiation study programs for the long-term needs of the CTR Technology program;

(6) The need to establish a major CTR effort in materials study for the near-term and long-term plasma confinement and fusion power reactor programs ;

(7) The need to develop talent and experience in the many diverse CTR related fields (other than surface and materials studies) such as: engineering design of coolant systems, mechanical design of systems subjected to high currents, cylical thermal and mechanica! stresses, remote assembly, disassembly and handling systems, tritium-fueling and handling systems, vacuum and pumping systems, energy storage and switching systems, experimenial plasma diagnostics anc plasma engineering physics relating to the device, neutronics of $14 \mathrm{MeV}$ neutrons, basic biological studies of $14 \mathrm{MeV}$ neutrons, radiological and environmental studies of a plasma source environment, basic solid state science studies, CTR related engineering, and others. 
II. RADIATION TEST FACILITY

The types of devices or concepts considered as possible test facilities can be classed into two groups: (A) Neutron Source and (B) Plasma Source.

\section{A. Neutron Source}

In this group the two systems reviewed were essentially acceleratortarget systems: (1) the LLL deuteron accelerator and rotating solid titanium-tricide (TiT) target, and (2) the LASL tritium-ion beam accelerator inceracting with a supersonic flow of deuterium gas.

\section{A.1 Rotating Target Neutron Source (LLL)}

The Rotating Target Neutron System at LLL (Ref. 15) is the most intense 2 to $3 \times 10^{12} \mathrm{n} / \mathrm{sec} 14-\mathrm{MeV}$ neutron source currently available. Although the source strength may not be intense enough to satisfy the high fluence needs of the CTR program, it may be sufficient for the initial study phases in the areas of surface physics and limited bulk radiation damage studies.

A summary of the specifications on the existing systems and the design parameters of the proposed upgraded facility are included in Table $V$.

The present operating conditions have been found to satisfy the fluence needs of the surface program. Measurable observations for surface studies have been made at fluence levels of $\sim 5 \times 10^{15} \mathrm{n} / \mathrm{cm}^{2}$ over an irradiation period of about $60 \mathrm{hrs}$. This dose was attained at a sample distance of $21.75 \mathrm{~cm}$ from the source. Higher fluence levels may be attained if a small sample (<3 $\mathrm{mm}$ dianeter) would be placed within $4 \mathrm{~mm}$ of the target. The maximum fluence attainable at this sample position and with a fresh target would be $22 \times 10^{17} \mathrm{n} / \mathrm{cm}^{2}$ for a $60 \mathrm{hr}$ irradiation period. However, since the source strength decreases with a target half-life of $700 \mathrm{mAh}$, the actual fluence available to the experimenter is closer to $1 \times 10^{17} \mathrm{n} / \mathrm{cm}^{2}$. 
TABLE V. Summary: Rotating Target $14 \mathrm{MeV}$ Neutron Source Facility (RTNS, LLL)

\begin{tabular}{|c|c|c|c|c|}
\hline \multirow[t]{3}{*}{ Concept Description: } & \multirow{3}{*}{$\underbrace{\text { Accelerator }}_{\begin{array}{l}\text { Current } \\
\text { Operating } \\
\text { Parameters }\end{array}}$} & \multicolumn{2}{|c|}{ - TiT Target System } & \multirow{3}{*}{$\begin{array}{l}\text { Ultimate } \\
\text { Goal }\end{array}$} \\
\hline & & $\begin{array}{l}\text { Propo } \\
\text { Desi } \\
\text { Parame }\end{array}$ & & \\
\hline & & Initial & $\overline{\text { Final }}$ & \\
\hline \multirow{4}{*}{$\begin{array}{r}\text { Deuteron Beam Energy, keV } \\
\text { Current, } \mathrm{mA}\end{array}$} & 400 & 400 & 400 & 600 \\
\hline & 15 & 40 & 150 & 500 \\
\hline & 6 & 16 & 60 & \\
\hline & 0.13 & 0.33 & 1.13 & \\
\hline Power Density, $\mathrm{kW} / \mathrm{cm}^{2}$ & 46 & 48 & 53 & \\
\hline Rotating Target Outer Diameter, $\mathrm{cm}$ & 23 & 38 & $>38$ & \\
\hline Target Speed, rpm & 1100 & 2000 & 5000 & 5000 \\
\hline \multirow{2}{*}{$\begin{array}{c}\text { Target Half }-1 \text { ife Hours } \\
\text { mAh }\end{array}$} & & 100 & 100 & \\
\hline & 700 & & & \\
\hline $\begin{array}{l}\text { Neutron Source Intensity } \mathrm{n} / \mathrm{sec} \\
\text { Small Sample Distance }\end{array}$ & $2 \times 10^{12^{c}}$ & $1 \times 10^{13^{d}}$ & $4 \times 10^{13^{d}}$ & $\sim 10^{14}$ \\
\hline From Target, $\mathrm{cm}$ & 0.4 & 0.4 & 0.4 & \\
\hline Geometry Factor, $\mathrm{cm}^{2}$ & 2 & $\sim 2$ & 2 & \\
\hline Flux at Sample, $\mathrm{n} / \mathrm{cm}^{2}-\mathrm{sec}$ & $1 \times 10^{12}$ & $7 \times 10^{12}$ & $2 \times 10^{13}$ & \\
\hline \multicolumn{5}{|l|}{ Accessibility, Number of } \\
\hline Experiments & 1 & 1 & 1 & \\
\hline Estimated Total System Power, MW & 0.05 & & 0.3 & 1.2 \\
\hline
\end{tabular}

accelerator Specifications $500 \mathrm{keV}$ @ $600 \mathrm{~mA}$.

${ }^{b}$ Ultimate Goal Dependent on Advanced Target Research and Development and High Current Density Transport Systems.

CMaximum Achieved Is $3.8 \times 10^{12} \mathrm{n} / \mathrm{sec}$ (c) $17 \mathrm{~mA}$ for 5 hours.

dDependent on Target Design Development.

Accessibility relates to the capability of accomnodating a number of experiments at the specified peak flux simultaneously. 
The current operational flux levels appear to be severely limiting to bulk radiation studies even with small-size samples. A continuous irradiation period of 260 days $\left(2 \times 10^{7}\right.$ seconds work year) would result in a total fluence of $<2 \times 10^{19} \mathrm{n} / \mathrm{cm}^{2}$ which is about a factor of ten less than the minimum fluences required by the bulk radiation studies.

(a) Target Design and Flux Limits

The neutron yield and lifetime of a tritiated target is dependent on the energy locally deposited by the deuterons. The consequent localized temperature rise results in the thermal dissociation, displacement of tritium by deuterons, and migration of tritium. The duration of the neutron yieid is therefore limited by the energy absorption capability (thermal properties) of the target material and the design technique of the heat removal system.

The rotating target system developed at LLL is operated so that al though the thermal spike of a target element within the beam area exceeds the dissociation temperature of the titanium tritide, the duration of the temperature pulse is short and therefore minimizes the effect on target life.

The approach by LLL to upgrade the total yield of the target is to develop a design having a time-temperature profile within the range of present target experience. An increase in beam current would therefore require a proportionate increase in the linear target velocity and a similar increase in the beam area. Essentially the power density incident on target is maintained constant and to within experienced intensities.

However, the gain in neutron flux available to an experimenter is strongly geometry dependent and does not neressarily scale directly with total yield. The flux at the experimental position $r_{0}$ on the axis normal to a disc source of radius $R$, and total strength $N_{t}$ is logrithmically 
dependent on the geometry as given by

$$
\varphi\left(r_{0}\right)=\frac{N_{a}}{4} \ln \left(\frac{R^{2}}{r_{0}^{2}}+1\right)
$$

where $N_{a}=N_{t} / \pi R^{2}$ is the source strength per unit area. A consistent analysis of the parameters specified in the summary, indicates that the peak flux levels available to the experimenter are expected to be $3.5 \times 10^{12}$ and $1 \times 10^{13} \mathrm{n} / \mathrm{cm}^{2}-\mathrm{sec}$ rather than the listed $7 \times 10^{12}$ and $2 \times 10^{13} \mathrm{n} / \mathrm{cm}^{2}-\mathrm{sec}$.

Therefore, it appears that the LLL RT-II will be limited to a maximum flux of $10^{13} \mathrm{n} / \mathrm{cm}^{2}-\mathrm{sec}$, and with a target half-life still in the range of $100 \mathrm{hrs}(15,000 \mathrm{mAh})$, the average dose rate would be $<10^{13} \mathrm{n} / \mathrm{cm}^{2}-\mathrm{sec}$.

A suggestion made was to consider the higher neutron yield potential of a LiT solid target and at a beam current of $250 \mathrm{~mA}$. The thermal properties of LiT (melting temperature $680^{\circ} \mathrm{C}$ ) are less favorable than TiT, and to operate the target at the lower thermal conditions, the beam area and hence source size would have to be increased markedly. Assuming that the surface power density capability of LiT is equal to that of TiT, then from the above flux relation, the peak flux for experiments would scale as the radius of the source for $r_{0}>R$ and not the total source strength as would be the case for $r_{0}>R$. Consequently, with an allowable surface power density much lower than that of the TiT target, the peak flux available may be independent of increasing the source strength by the higher neutron-yield LiT target (or other tritiated compounds) and higher beam currents.

(b) The Utility of RT-II in Surface and Bulk Radiation Program It appears that a limit of $10^{13} \mathrm{n} / \mathrm{cm}^{2}-\mathrm{sec}$ can be expected from the LLL proposed Rotating Target (RT-II) systen with TiT, as well as with other types of solid target systems. At this level the surface radiation effects 
can be studied at higher fluences. The use of this proposed LLL RT-II system has been included in the Surface Radiation Program plan (as outlined in Table VIII).

At these proposed flux levels it may be feasible to satisfy some area of bulk radiation studies with small-size samples. A minimum fluence of $\sim 10^{20} \mathrm{n} / \mathrm{cm}^{2}$ may be attainable for a 260 day irradiation period. However, the actual available averaged flux over this time span may be lower because of the finite target half-life.

In the "miniaturization" of the test sample an important aspect to consider is that the relative sample size with respect to the source size and geometry strongly determine the spatial flux distribution on the test specimen. At positions of peak source intensities (close-in to target), the flux distribution could vary by factors of 3 or 4 and more depending on: the relative sizes of the target and test sample; the ion-current distribution on target; and the degree of anisotropy of the neutrons emitted by the target. In the current LLL system, the flux distribution varies by about a factor 2 from the center to the edge of a $6 \mathrm{~mm}$ radius test specimen at the flux peak position of about 4 to $5 \mathrm{~mm}$ distant from a $5 \mathrm{~mm}$ radium disk of the isotropic neutron source.

The Bulk Radiation Effects Experiments outlined in Table III include the need for an insitu capability of 50\% uniformity of flux over the test specimen to study the dimensional stability of structural materials. A more restrictive insitu capability of $10 \%$ uniformity of flux over a $5 \mathrm{~cm}$ length specimen is required to investigate the radiation controlled creep rates in the structural materials. The above two classes of experiments will require test facility capability not readily attainable in the LLL rotating target 
system. The uniformity of the flux distribution available for experiments improves as the test specimen is further removed from the source. However, this requires a test position at much lower flux levels and testing at much lower fluences.

\section{(c) Accessibility Limits}

A figure of merit for the performance of a test facility is the capability and flexibility of the system to accommodate a range of experimental needs, and the number of experiments which can be performed simultaneously in order to provide a broad base of support for the total facility (i.e. the operating costs per experiment). The LLL rotating target system is essentially a limited access machine in that only one small-size sample can be located at the peak flux position ( $4 \mathrm{~mm}$ distance). The accessibility index is introduced in the summary and is normalized to one experiment at the peak flux position. Other small-sized samples may be irradiated simultaneously but these would be in much lower flux regions.

\section{(d) Remarks}

The proposed Livermore program for developing rotating and accelerating systems (RT-II) yielding higher intensity $14 \mathrm{MeV}$ neutrons will mainly satisfy the near-term needs of the Surface Radiation programs. Expanding the proposal to include ion-accelerators and photon source capabilities in combination with the neutron source offers an extended experimental capability for surface studies. The accelerator systems exist, are commercially available, and can be arranged into any desired assemblage suitable for a limited phase of the experimental program.

The simultaneous use of several such existing systems for surface radiation experiments has already been scheduled or planned to start in FY 1975 
by the surface investigators at various laboratories. The experiments are planned to continue over the next few years and are expected to contribute importantly to the initial basic understanding of wall emissions and reaction mechanisus resulting from several continued radiation fields.

A.2 Intense $14 \mathrm{MeV}$ Neutron Source (INS) Facility (LASL)

The neutron source facility proposed by LASL (Ref. 16) is based on the concept of two intersecting beams involving the supersonic flow of a deuterium gas interacting with an accelerated $270 \mathrm{keV}$ tritium-ion beam current of 1.1A. The concept utilizes a nozzle design and wind turitiel conditions to attain a jet velocity of Mach 8 to Mach 9. The tritium-ion beam is injected and focused into an interaction zone in the immediate region of the nozzle where the deuterium gas density is maximum $\sim 2 \times 10^{19} \mathrm{D}_{2} / \mathrm{cm}^{3}$. The anticipated $(D, T)$ reactions in the reaction zone volume of $<1 \mathrm{~cm}^{3}$ are computed to yield a total $14 \mathrm{MeV}$ source strength of $210^{15} \mathrm{n} / \mathrm{sec}$. The specified proposed fiux incident on a small-size test specimen is anticipated to be approximately $10^{14} \mathrm{n} / \mathrm{cm}^{2}-\mathrm{sec}$ at a $7 \mathrm{~mm}$ distance from the source.

A summary of the characteristics of the proposed facility is included in Table VI.

The concept of the system and subsystems is in a preliminary conceptual stage and design details are limited. However, there are general technical areas involved in which a technical assessment and evaluation can be made in judging the feasibilicy of developing the concept into a test facility.

(a) Beam Transport and Multistage Differential Pumping

Gas pressures as low as $10^{-5}$ torr in the beam transport region may be required in order to maintain a well focused beam into the nozzle area $(<1$ $\mathrm{cm}^{2}$ ). Serious losses of deuterium from the gas jet into the triton beam 
TABLE VI. Summary: Intense $14 \mathrm{MeV}$ Neutron Source Facility (INS, LASL)

\begin{tabular}{|c|c|}
\hline \multicolumn{2}{|c|}{$\begin{array}{l}\text { Concept Description: Tritium-Ion Beam } \\
\text { Accelerator-Deuterium Supersonic Jet Target }\end{array}$} \\
\hline \multirow[b]{2}{*}{ Triton Beam Energy, keV } & $\begin{array}{l}\text { Proposed Design } \\
\text { Parameters }\end{array}$ \\
\hline & 270 \\
\hline Current, $A$ & 1.1 \\
\hline Power, kW & 300 \\
\hline Focused Beam Area at Target, $\mathrm{cm}^{2}$ & $<1$ \\
\hline Beam Current Density, $\mathrm{A} / \mathrm{cm}^{2}$ & $>1.1$ \\
\hline Beam Power Density, $\mathrm{kW} / \mathrm{cm}^{2}$ & $>300$ \\
\hline \multirow{2}{*}{$\begin{array}{c}\text { Deuterium Gas Target Density, } \mathrm{D}_{2} / \mathrm{cm}^{3} \\
\text { Gas Flow Area, } \mathrm{cm}^{2}\end{array}$} & $2 \times 10^{19}$ \\
\hline & 1 \\
\hline Volume Deuterium Gas Target, $\mathrm{cm}^{3}$ & 1 \\
\hline Neutron Source Intensity, $\mathrm{n} / \mathrm{sec}$ & $8 \times 10^{14}$ \\
\hline $\begin{array}{l}\text { Small Sample Distance to Surface } \\
\text { of Target Region, } \mathrm{cm}\end{array}$ & 0.7 to $1.0^{a}$ \\
\hline \multirow{3}{*}{$\begin{array}{l}\text { Geometry Factor, } \mathrm{cm}^{2} \\
\text { Neutron Flux at Sample, } \mathrm{n} / \mathrm{cm}^{2}-\mathrm{sec} \\
\text { Accessibility, Number of Experiments }\end{array}$} & $8 \quad 11$ \\
\hline & $10^{14}$ to $7 \times 10^{13^{b}}$ \\
\hline & 4 \\
\hline Estimated Total System Power, MW & 2 \\
\hline \multicolumn{2}{|c|}{$\begin{array}{l}{ }_{\text {Based on realistic distance in nozzle area. }} \\
{ }^{b} \text { Scaled from } 10^{14} \mathrm{n} / \mathrm{cm}^{2}-\mathrm{sec} \text { at } 0.7 \mathrm{~cm} \text { to } 1 \mathrm{~cm} \text { on linear } \\
\text { distance dependence. }\end{array}$} \\
\hline
\end{tabular}


tube due to gas scattering in the differential purning stages is to be expected. This problem will have to be studied in more quantitative detail since it does imply a serious design constraint on the differential pumping techniques. The consequence is that the degree of focusing may have to be relazed resulting in a more extensive spatial distribution of the target, which in turn would mean a directly proportionate reduction in neutron source strength.

However, upper limits to the allowable size of the reaction volume will be imposed by the wind tunnel and nozzle design conditions. A reaction volume of $1 \mathrm{~cm}^{3}$ requires very effective focusing for an extended ion beam. There is a need to understand the space charge effects within the ion beam at high currents in order to maintain focus under the proposed wind tunnel conditions.

In the proposed design after the triton beam has been accelerated to full energy it is subjected to astigmatic focusing for the transport path to the first aperture of the differential pumping system. The space charge effects will become important when the beam is focused to $20.6-1.0 \mathrm{~cm}$ diameter to pass through the series of apertures of the differential pumping system and into the gas-jet target. The dispersion of the triton beam currents of $21 A$ through apertures of $\sim 1 \mathrm{~cm}$ diameter could reach from 40-60\% in traveling distances of only 4-6 cm. The consequences are that differential pumping systems with enough stages and small enough aperatures to be effective even within this range of beam dispersions would have to be designed to fit within a small linear distance.

In the transition region of focusing, the loss of tritium would reduce the ion current entering the intersation zone with the consequent reduction 
in the source strength estimated at $10^{15} \mathrm{n} / \mathrm{sec}$. The preliminary proposed design parameters are not pessimistic and therefore the quoted intensities and available fluxes may be overestimates.

A problem that may develop in the accelerator and beam transport system is that with an ion source efficiency of $50 \%$, the tritium-ion current in the ion source region is approximately $2 \mathrm{~A}$. The disposition of $1 \mathrm{~A}$ of tritium ions and the radioactive decay may be such that insulator lifetimes would be shortened. The maintenance and decontamination of this system may pose difficult design problems.

(b) Source Accessibility

The physical introduction of a multistage differencial pumping system would imivediately compromise the radial accessibility of the source to the experimenter. A reasonably compact design of a pumping system will 1 imit the close access to the interaction volume and effect a reduction of the flux incident on the test specimen to a level much lower than $10^{14} \mathrm{n} / \mathrm{cm}^{2}-\mathrm{sec}$.

With multistage differential pumping and heat dissipation systems in the vicinity of the jet nozzle, an accessibility merit figure of 4 is assigned to this concept. Small-size test samples may be placed on oniy four sides of the interaction region.

(c) Aerodynamics of Supersonic Jet-Flow

The classical analysis of nozzle design applied to estimate the shock front and peak gas density, is inadequate to describe the aerodynamics of jet nozzle systesm with a $300 \mathrm{~kW}$ heat load. This may prove to be a severe restricition on the concept since the heat load may choke or change the shock from characteristics emitted from the nozzle system. As a minimum effect, the anticipated gas density should be decreased under a heat load and just 
as important the redistribution of the pressure front will have to be conpensated for by a redirection and/or refocusing of the trizium-ion beam. The resulting linearly extended source distribution has the consequence of reducing the neutron flux available for experiments.

The jet nozzle design integrity and the lifetime will be limited under the radiation field of scattered energetic deuterons, tritons, and the reaction products, neutrons, alpha particles and photons. The consequent sputtering, erosion and in particular blistering of the nozzle surface, my effect the anticipated supersonic laminar flow pattern.

In summary, then, there are major technological problems which may greatly affect the feasibility of combining the separate principle concepts involved. Extensive research and development in many of the susystens of high current bean transport and focusing accelerator systens, multistage differential pumping systems, wind tunnel and nozzle design, and nore important in the severe interfacing problens of combining these systens will be necessary to develop this concept into a neutron test facility.

(d) Surface and Bulk Radiati on Studies

The flux levels of $<10^{14} \mathrm{n} / \mathrm{cm}^{2}-\mathrm{sec}$ anticipated in the proposed test facility would extend the neutron irradiation phase of the surface program into a study of surface effects as a function of intensity and fluence. The intensity may allow some shaping of the neutron energy spectrin to investigate energy dependent effects. However, since the accelerator-gas target is not a plasma source, filtering of background energetic particles and reaction products will be necessary to isolate the desired neutron effect.

If the flux level of $210^{14} \mathrm{n} / \mathrm{cm}^{2}-\mathrm{sec}$ is attainable, then bulk radiation effects studies on small-sized test samples can be extended to fluences of 


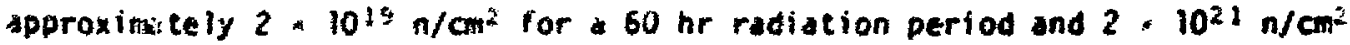
for 260 day period. Here again to produce unmbiguously the neutron dependent effects. the background radietion of deuterons. tritons, alpha particles. and photons would have to be screened by appropriate filters. The introduction of filters between source and test specimen would increase the separation distance and result in iower flux at the saple.

The general coments on the source geometry effects referred to in the section on the Livermore AT-II system apply to the gas-jet target. However. the expected higher flux leve is would allow test specien positions in regions where the unifonity of flux distribution way be nore readily satisfied for the butk radiacion program.

The generslly higher fluxes would extend the type of bulk effects which can be studied with small-size samples: cemperature dependent swelling. creep. fatigue strength and perhaps material ductility.

\section{(e) Remarks}

The gas-jet target system has the potential of making available a 14 MeV neutron source of sufficient intensity to satisfy the more long-range basic studies of the bulk-radiation effects program. Of particular inportance would be establishing analytical modeling correlations between neutron radiation and ion-bonbardment techniques.

The emphasis in the developmental program for this concept should be centered on establishing the feasibility of each of the major subsystems independently and in combination. High priorities should be assigned to demonstrating the effect of the heat load on the deuterium gas-jet density and feasibility of coupling the ion-accelerator beam-focusing system and the jet-nozzle system (with the heat laad) through the multi-stage differential pumping system. 


\section{B. Plasma Source}

An important aspect of a thermal plasma device is that the simultaneous yield of neutrons, energetic particles, bremsstrahlung, soft $X$-rays and synchrotron radiation, makes possible the study of the synergetic effects of the radiation fields on the vacuum wall materials. The total plasma radiation environment may more closely simulate the integral effects anticipated at the first wall of a fusion device or reactor, but at lower intensity. The simulation results from the fact that in thermonuclear plasma reactions the relative intensity ratios of the neutrons and alpha particles, and the bremstrahlung radiation are constant and independent of the type of confinement device. The intensities are each proportional to the square of the ion-density. The relative ratio with respect to the synchrotron radiation is inversely proportional to $\beta$ (the ratio of plasma to magnetic field pressure) and as such is apparently device dependent. However, the extent of this dependency will rely on the self-absorption properties of the plasma to this radiation.

A further correlation between the plasma test source and thermonuclear confinement machines may be established from the presence of a plasma and magnetic field interface region in both systems.

Selective filtering of the separate radiation components may introduce a capability for differential and integral surface effects studies and in addition bulk radiation effacts for neutron fluxes of sufficient intensity.

\section{B.1 Dense Plasma Focus (DPF)}

of the many types of currently operable plasma devices, the dense plasma focus (Ref. 17-21) has been consisiently and systematically developed and scaled 
to yield thermonuclear plasmas of deuterium gas with (D,D)-neutron source strength thus far achieved at an intensity of $1.2,10^{12} \mathrm{n} / \mathrm{pulse}$ in approximately $l \mathrm{~cm}^{3}$ volume.

The dense plasma focus (DPF) is a plasma discharge with plasma densities $n>10^{19} / \mathrm{cm}^{3}$, temperature in the range of $5-10 \mathrm{keV}$, and a duration time of 100-200 nsec. The focus is a two-dimensional pinch formed on the central axis and at the end of a finite length of two cylindrical coaxial electrodes. An instantaneously applied voltage across the insulated electrodes induces an initial gas breakdown at the closed-end of the coaxial electrodes. The radially directed current-sheath formed with its self-induced poloidal magnetic field accelerates the plasma, via the $\underline{\mathrm{J}} \times \underline{\mathrm{B}}$ force, axially toward the open-end of the electrode system. The magnetic energy-density generated in the system is rapidly converted to plasma energy during the current-sheath's radial collapse toward the axis. The plasma is adiabatically compressed by the field pressure and a fraction (approximately 5-10\%) of the ions are confined and form a thermal plasma focus. The non-thermalized fraction of the ions escape axially in a highly focused beam through the poloidal field singularities.

Recent experimental results and analysis consistent with these results, have been translated into a generally accepted model describing the characteristic behavior of the plasma (Refs. 18-21). In some devices, the initial intensely pinched plasma formed at the time of collapse, yields a small burst of neutrons with a $40 \mathrm{nsec}$ lifetime. The axial plasma column becomes unstable in the compressed state and is disrupted by macroscopic $m=0$ instabilities. The consequent disruption and turbulent motion enhances the ohmic heating of the plasma and results in yielding the main (second) burst of neutrons with 
a 100 nsec pulse width. In other designs, only a single burst of neutrons with a 100 nsec pulse width is observed.

At high enough gas filling pressures, the neutron and $X$-ray emission are predominantly of thernonuclear origin with neutron energy spectrun at $2.5 \pm 0.1 \mathrm{MeV}$ and an isotropic distribution. A small fraction of the neutrons may result from an acceleration ion beam-target mechanism characterized by energies of approximately 2.8-3.2 MeV and a marked anisotropic distribction along the axis.

Experiments have shown that at high pressures ( $>10 \mathrm{Torr}$ ), the focus is a thermalized plasma yielding thermonuclear neutron and $X$-ray radiation. At low pressure conditions ( $<2-3$ Torr) the ion-accelerator mechanism is enhanced until at low enough pressures the acceleration-target mode is the predominant mechanism for the neutron source (Refs. 18-21). In this operating regime and depending on the design of the device, there exists a hard $x$-ray component arising from the ion-beam interaction on the electrode face.

The utilization of the dense plasma focus device as a radiation test facility for the CTR program will therefore require that the device be operated in the high pressure mode in order to more closely simulate thermonuclear plasma source.

\section{(a) Neutron Scaling}

The scaling laws for $(D, D)$ neutrons can be related to the plasma current at the time of maximum compression and heating, and in turn to the stored capacitor bank energy $W$. From the general reiations between the significant parameters

$$
I^{2} \propto \mathrm{nRT} \propto \mathrm{B}^{2} \alpha \mathrm{W}
$$

and from the neutron production rate relation

$$
i_{n} \approx n^{2}\langle\sigma v\rangle
$$


where ; is the Mawellian averaged cross section for the $U-D$ reaction, the neutron yield is expected to increase with the square of the capacitor bank energy,

$$
N_{n}+W^{2}
$$

A general trend in this direction can be seen in Fig. I (Ref. 22), of the observed neutron yields as a function of capacitor bank energies for a variety of plasma focus experiments. The optimization of the neutron yield depends on the applied voltage, initial gas pressure, plasma volume, gas purity and electrode design so that the quantitative relationship exhibited by the plot must be qualified to account for the varied devices and diverse experimental conditions. The significance of the plot is in the graphic demonstration of the consistent and continuous increase in the neutron yield as the plasma focus devices have been scaled in energy and improved in design over the past years.

Experimental values of the yield dependence with the exponent of the input energy has ranged between 1.5 and 2.5 as reported by many investigators. The deviation from the square law is also influenced by the electrical circuitry of the total system, i.e. impedance matching, capacitance, inductance, voltage and current. The reproducibility of neutron production has been reported as varying within a factor of two, whereas some experiments have been reported as reproducible under more controlled conditions.

(b) DPF Device as a Plasma Source

In order to scope the potential for developing the plasma focus discharge into a plasma radiation test source, the scaling laws adopted for neutron production estimates have been based on the systematic set of Mather's Systems experiments conducted at LASL (Ref. 23). Figure 2 (Ref. 23) 


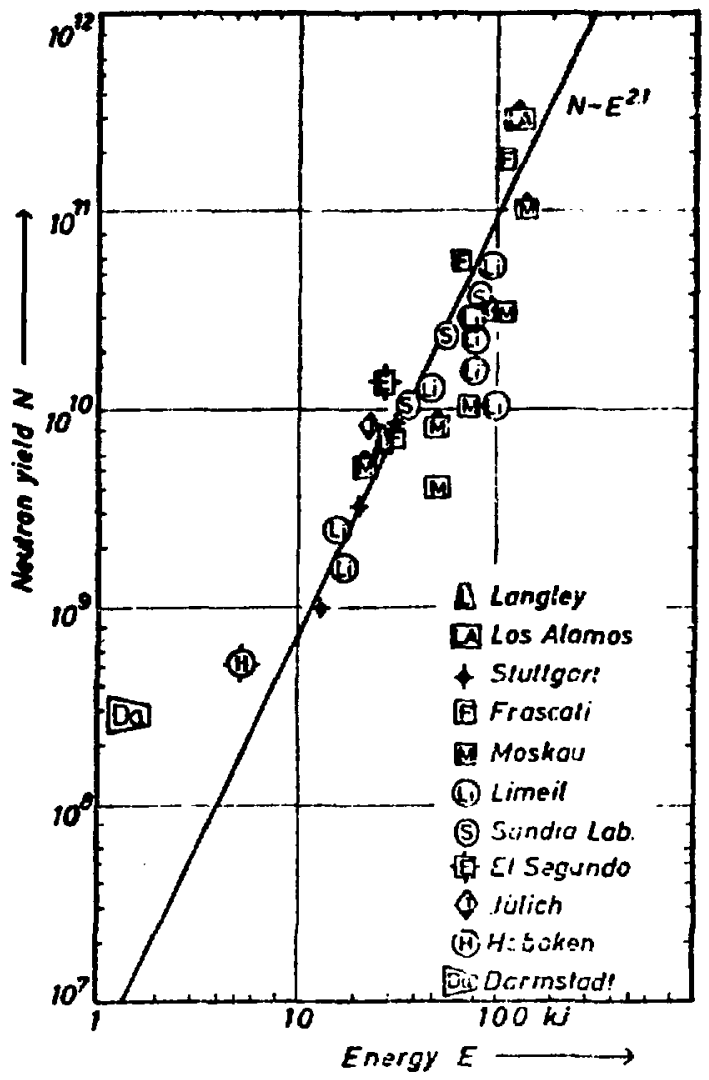

Fig. 1. Neutron Yields $N$ vs Energy $E$, Assembled by H. Rapp (Ref. 22) 


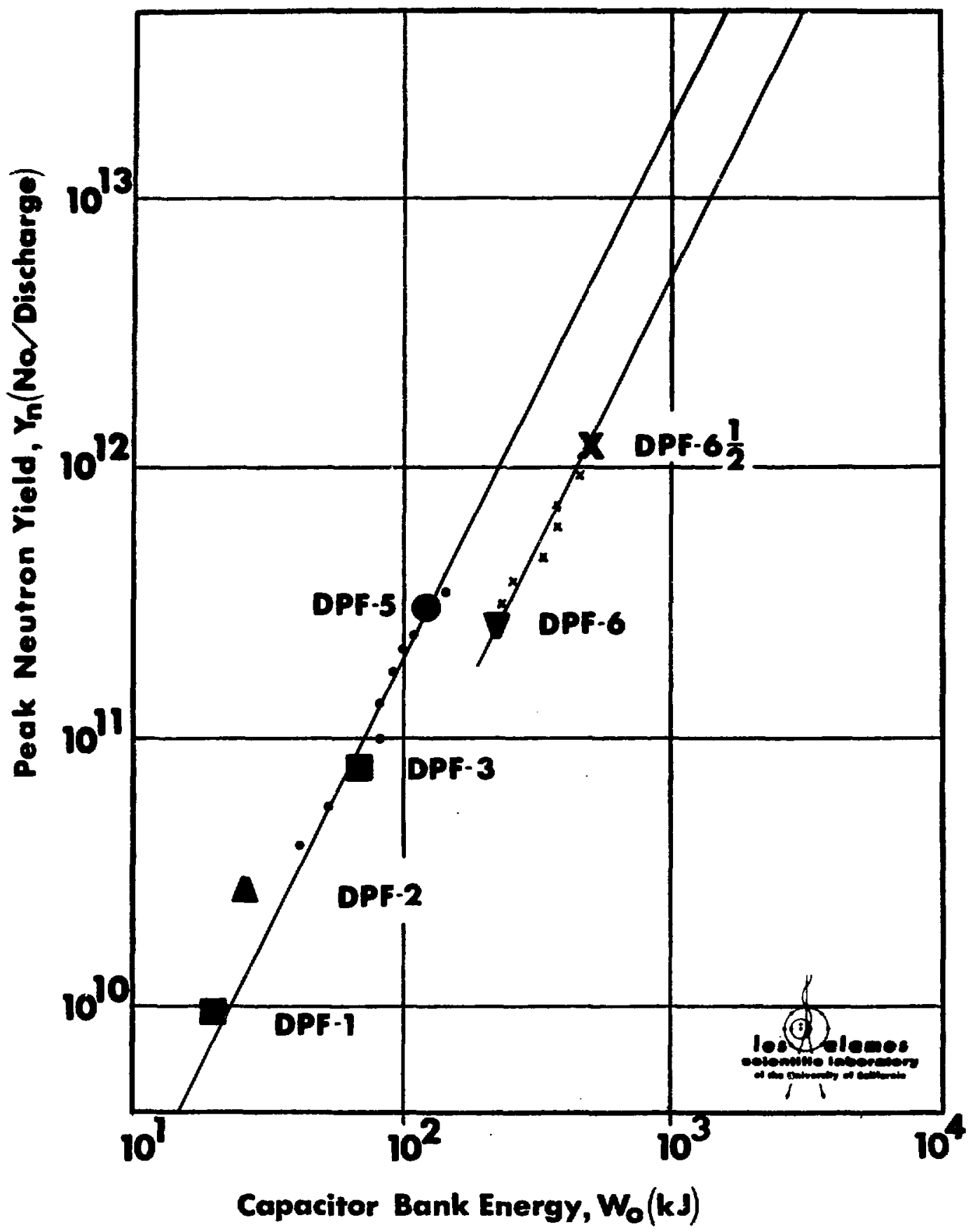

Fig. 2. Peak Neutron Yield vs Capacitor Bank Energy 
contain the maximum neutron yield for several DPF systems. The set of experiments performed with the DPF-1, DPF-2, DPF-3 and DPF-5 devices were under conditions optimized for neutron production. The dependence of the yield follows the square power of the input bank energy over the range, $18 \mathrm{~kJ}-20 \mathrm{kV}$ to $120 \mathrm{~kJ}-50 \mathrm{kV}$. The neutron yield at $120 \mathrm{~kJ}-50 \mathrm{kV}$ (DPF-5) is reported as $2.65 \times 10^{11} \mathrm{n} / \mathrm{pulse}$.

The set of experimental yield values also scale to the square of the input bank energy for the range of $200 \mathrm{~kJ}-45 \mathrm{kV}$ to $420 \mathrm{~kJ}-46 \mathrm{kV}$. The maximum neution yield reported is $1.2 \times 10^{12} \mathrm{n} / \mathrm{pulse}$ at the capacitor bank energy of $420 \mathrm{~kJ}$. The lateral displacement of the two curves has been partly attributed to the oferational conditions of the DPF- 6 and DPF-6.5 devices for optimum $x$-ray production. This involves placing a solid tungsten insert into the central electrode, and at times placing a tungsten stud extended from the end of the central electrode designed in a parabolic form. The tungs ten rod introduces a high $Z$ impurity which may tend to limit the plasma temperature and in turn the neutron yield. As indicated in Fig. 2, the displacement results in a reduction of the neutron yield by a factor of 23.5 .

One of the pressing set of experiments to perform on this device, is to verify the magnitude of this factor. There are several modifications suggested by LASL to optimize the device for neutron production: (1) remove tungsten rod, (2) flatten the electrode end and (3) introduce a nole in the central electrode to reduce impurities and hard $X$-ray radiation.

The overall neutron production scaling for all the devices follows a $3 / 2$ power dependence on the capacitor bank energy. Therefore for the purpose of scoping potential design parameters for a radiation test facility, the neutron yields are presented in a range of scaling with the square and the $3 / 2$ power of the bank energy. 


\section{(c) Deuterium-Tritium Gas}

The neutron production for a 50-50 deuterium-tritium gas mixture in a plasma-mode focus is expected to scale as the ratio fo the Maxwellian averaged cross section, $\sim 100$ for equal total number density. The series of LASL experiments resulted in $(D, T) /(D, D)$ ratios of approximately $80-100$, which are consistent with the expected ratio for plasma temperatures in the range of $1-10 \mathrm{kel}$.

A similar experiment perforined at Limeil, France, ${ }^{20}$ yielded a ratio of about 30 . The operational characteristics of the two devices were different in that the LASL experiment indicated an increase in the $(D, T)$ pulse width, as had been anticipated, whereas, the Limeil experiment showed a decrease in the pulse width.

A limited series of experiments were performed by the Physics International Company on a $500 \mathrm{~kJ}$ - $20 \mathrm{kV}$ plasma focus device using a 50-50 deuterium-tritium gas mixture. The maximum yield of $6 \times 10^{12} \mathrm{n} / \mathrm{pulse}$ were reported before the experiments were terminated. The low yield has been attributed to the electrode design and operating conditions which were not optimized for neutron production.

The generally accepted scaling factor for a $(D, T)$ system is taken as approximately 80 . However, this value was established at low capacitor bank energies and should be experimentally verified in the more advanced systems. A set of experiments should be planned for the LASL $720 \mathrm{~kJ}-60 \mathrm{kV}$ system at several capacitor bank energies and voltages including a measurement at $420 \mathrm{~kJ}-46 \mathrm{kV}$.

(d) Pulsed Energy Storage and Transfer System

The repetitive pulsing characteristics of a plasma device will be an important consideration in determining the development potential as a 
radiation test facility. Repetition rates of several pulses per second are necessary to not only establish feasibility but would introduce important options in the scaling program. For plasma focus devices, the total scaling is $\in$ ffected by the capacicor bank energy and repetition rate. Options will exist to allow high-energy at low repetition rates or low-energy at high repetition rates for a given total power level.

Several of the $(D, T)$ plasma source concepts are inherently or basically pulsed systems. The major problem in this area is the energy storage and transfer system. The feasibility of developing a radiation facility in a timely and meaningful manner to the overall CTR program is critically dependent on the approach taken for the energy storage system. For storage systems in the range of several megajoules, conventional capacitor bank systems with conventional spark-gap energy switching systems appear capable of being developed with repetition rates in the order of several pulses per second. This eases the necessity of having to depend primarily on the development of the superconducting magnetic energy and transfer systens.

A modest development program to design commercially producible capacicors and switching systems having a lifetime of $>10^{7}$ cycles would not introduce a time-delay in the utilization of some of the proposed pulsed devices.

(e) Potential Utility of a DPFRTF

A summary of the potential design parameters for developing the DPF device into a radiation test facility is given in Table VII. In scaling the experimental data to facility design parameters, an upper limit of $10 \mathrm{~mW}$ was adopted as a reasonable operating power level for a research test facility (e.g. fission research reactors). This power level allows a flexibility 
TABLE VII. Sumary: Dense Plasma Focus (DPF, LASL)

\begin{tabular}{|c|c|c|}
\hline & $\begin{array}{l}\text { Current } \\
\text { Operating } \\
\text { Paraweters }\end{array}$ & $\begin{array}{l}\text { Scoping } \\
\text { Potential } \\
\text { Parameters }\end{array}$ \\
\hline Capacitor Bank Energy, kJ & 420 & 2000 \\
\hline Voltage, kV & -46 & $\sim 60$ \\
\hline Peak Current, MA & 2.3 & $\sim 5$ \\
\hline Time of Peak Current, Hsec & $2-3$ & $2-3$ \\
\hline Gas Mixture & $(D, D)$ & $(D, T)$ \\
\hline Gas Pressure, Torr & $15-22$ & $15-22$ \\
\hline Electrode Length, $\mathrm{cm}$ & 52 & 52 \\
\hline Outer Electrode OE-Diameter, $\mathrm{cm}$ & 15 & 15 \\
\hline Inner Electrode IE-Diameter, $\mathrm{cm}$ & 10 & 10 \\
\hline Neutron Pulse Width, nsec & 100 & 100 \\
\hline Neutron Yield, ${ }^{b} \mathrm{n} / \mathrm{pulse}$ & $1.2 \times 10^{12}$ & $1 \times 10^{15^{c}}$ to $2.2 \times 10^{15^{d}}$ \\
\hline Repetition Rate, pps & & 5 \\
\hline Source Intensity, $n / \sec$ & & $5 \times 10^{15}$ to $1.1 \times 10^{16}$ \\
\hline $\begin{array}{l}\text { Sample at OE Surface } \\
\text { Geometry Factor, } \mathrm{cm}^{2}\end{array}$ & & 700 \\
\hline Flux at Sample, $\mathrm{n} / \mathrm{cm}^{2}-\mathrm{sec}$ & & $\begin{array}{l}7 \times 10^{12} \text { to } 1.5 \times 10^{13} \\
\left(2 \times 10^{13^{e}}\right)\left(4.5 \times 10^{13^{e}}\right)\end{array}$ \\
\hline Accessibility, f Number of Experiments & & 8 \\
\hline Estimated Total System Power, MW & & 10 \\
\hline
\end{tabular}

${ }^{a}$ Scaling based on Mather's Syatems Experinenta optimized for X-ray production.

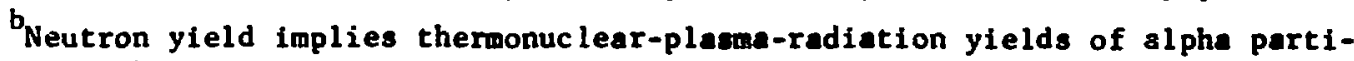
cles, bremsstrahlung, and photons.

c Scaling source yields to the $3 / 2$ power in capacitor bank energy and (DT)/(DD) cross-section ratio of 80 .

'Scaling source yields a in $c$ above except to the square in capacitor bask energy .

EPotential scaling factor of 3 for Mather's Syatems optinized for neutron production.

f Accessibility relates to the capability of accomodating a number of experiments at the spectfied peak flux simultaneously. 
in setting the capacitor bank energy and repetition rate to meet the needs of surface and bulk materials program provided the problem of cooling the electrode is not unsolvable. A $2 \mathrm{MJ}-60 \mathrm{kV}$ system is a factor of 5 greater than the currently achieved operating experience on the LASL $420 \mathrm{~kJ}-46 \mathrm{kV}$ system. This extrapolation will eventually be decreased to factors of 3 and 2 as experience is gained from the $1 \mathrm{MJ}-40 \mathrm{kV}$ experiments as scheduled in Fig. 3.

The extrapolated neutron source strength is within the range of $5 \times 10^{15}$ to $1 \times 10^{16} \mathrm{n} / \mathrm{sec}$ for a 5 pps repetition capability. This source intensity is an order of magnitude or more greater than the neutron facilities previously considered. Achieving these operating conditions makes possible much higher flux levels available for experiments depending on the erigineering layout design of the facility. A vertical installation allows a complete radial access to the plasma source. The positioning of the test specimens at the radius $(7.5 \mathrm{~cm})$ of the outer-electrode $(\mathrm{OE})$ will not perturb the formation of the focus. The geometry factor of $700 \mathrm{~cm}^{2}$ would then make available a fiux intensity of $7 \times 10^{12}$ to $1.5 \times 10^{13} \mathrm{n} / \mathrm{cm}^{2}-\mathrm{sec}$ depending on the scaling with the capacitor bank energy. As listed in the summary, if experiments indicate that a factor of 3 is consistent for an optimized neutron production mode, then flux levels of $2 \times 10^{13}$ to $4.5 \times 10^{13} \mathrm{n} / \mathrm{cm}^{2}-\mathrm{sec}$ may be available for experiments.

\section{(f) Accessibility}

At the distance of the $\mathrm{OE}$, large-size test samples can be accommodated (1-2 cm width, segmented or non-segmented annular strips in the plane of the focus). The capability for large-size testing at the flux levels indicated, introduces the possibility of meeting the needs of not only the surface program but also a broader scope of experiments in the bulk-radiation program. 
Fig. 3. CTR Neutron and Plasma Source Concepts, and Related Devices Development

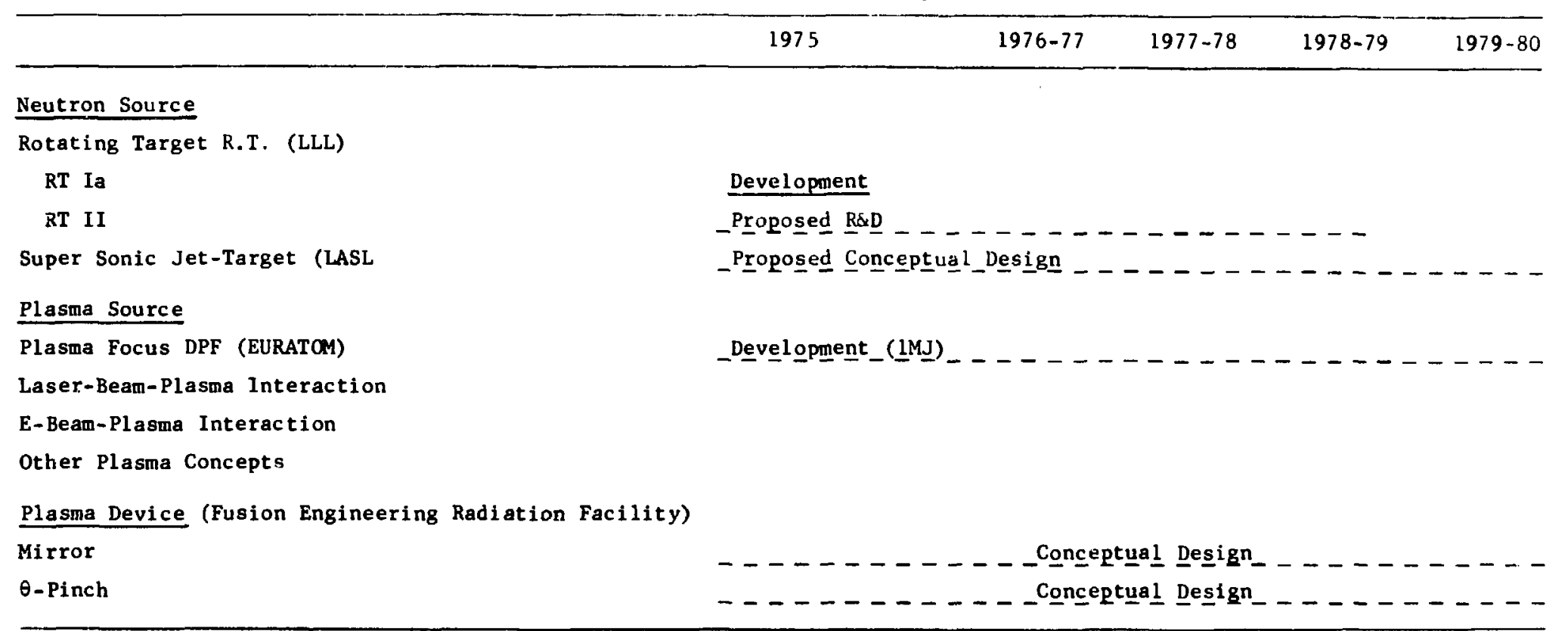

CTR Plasma Confinement Program

Princeton PLT

Princeton PDX

LASL SYLLAC

LLL Small Mirror - 2X-IIB (Pulsed)

LLL Mirror Baseball II, MX I, 2X-II Advanced

GA Doublet III

Fusion Test Reactor TFTR (Tokamak D-T Burner)

FTR-2 (Mirror or $\theta-$ Pinch D-T Burner)

EPR (Experimental Power Reactor)
Development $\ldots \ldots$ Experimental Program

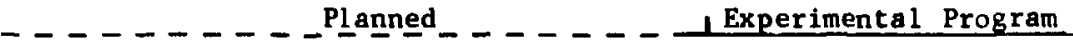

L Experimental Program

- - Experimental Program $^{-}$

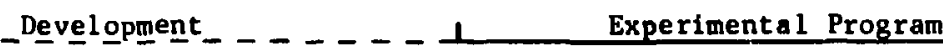

Development

Experimental Program

$$
\text { L }- \text { Degign }_{-}-L_{\text {L_ Construction }}
$$
Pöint
Decision Point $L-$ Design Construction Decision Point $(1980)-$ Design $^{L}-\frac{1}{\text { Operational }}$ (1985) 
The current-sheath forming the focus is close-in toward the open-ended coaxial electrode system. This may allow small-sized samples to be placed (off-axis) closer to the focus that the $O E$ distance. This access possibility will effect a 2 or 3 fold improvement in the geometry factor and correspondingly higher fluxes for experiments.

The radial geometrical layout of the radiation facility and the relatively large radius of the $O E$ gives the focus device the flexibility of accommodating many independent and diverse experiments at the same level of radiation. High fluence insitu experiments may be performed simultaneously and without interfering with those experiments having low fluence requirements.

An accessibility merit figure of 8 is based on locating test specimens at the 4 cardinal and 4 intermediate radial positions.

(g) Upgrading Options for the Radiation Facility

Referring to Taule VIII, the Surface Science Program needs in 1977 may be approached with a plasma source of $2 \mathrm{MJ}$ at repetition rates of 1 pps. The needs outlined in 1978 may be attained by scaling the repetition rate to 5 pps. If such a plasma source can indeed be designed, then the posibility exists of improving the source strength by scaling the energy of the capacitor bank to $5 \mathrm{MJ}$ at the lower pulsing rate of 2 pps.

The scaling by capacitor bank energy would have to depend on the experience gained in operating at lower bank energies. It may develop that the focus is found to be current limited, voltage limited or both, in which case the upgrading of the facility would be through the pulsing rate. If these limits are not ubserved in the range of the above operatinn levels, then the facility has the potential of meeting the longer-term requirements 
TABLE V111. Surface Science Program and Radiation Test Facilities

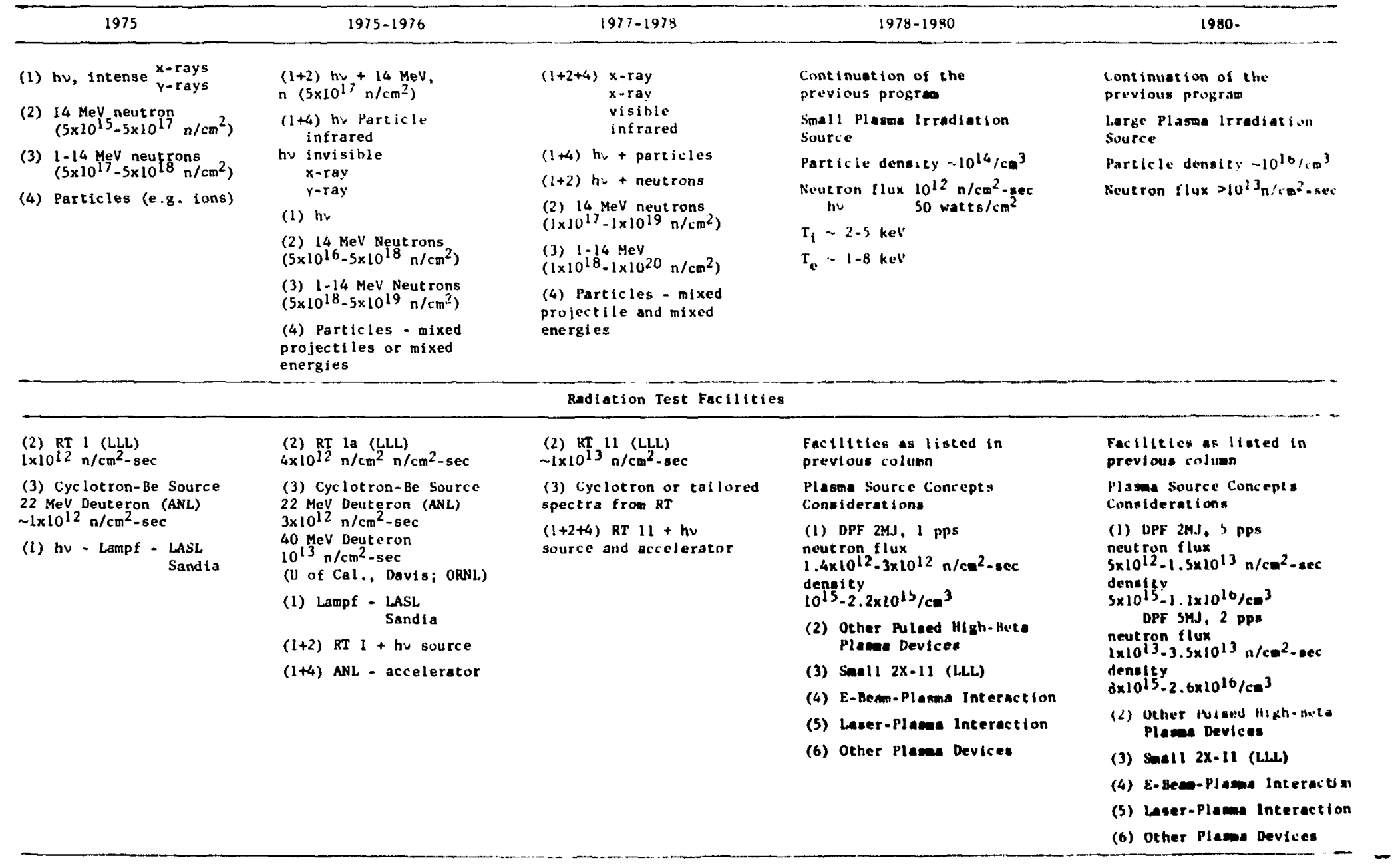


of both the surface and bulk radiation programs. There are many options and combinations of options: scaling in capacitor bank energy, scaling in pulsing rate, and improved geometry factors that should be explored in a more detailed facility design study and an expanded experimentation with large-scale plasma focus devices.

(h) Pulsing vs. Steady State Testing

The surface and bulk test data obtained from a pulsed testing facility may not be directly applicable for designing steady state fusion power reactors. However, the large scale plasma confinement experiment reactors planned for the next 15 years are essentially pulsed or quasi-steady state. Radiation rate effects and cyclic effects on damage to surface and structural materials are important to the fundamental understanding of radiation field interaction with solid matter as well as to the success of the confinement program. The surface and bulk radiation effects of pulsed and quasi-steady state testing will be of interest for fusion power reactors involving pulsed (theta-pinch and laser-ignition) and quasi-steady state (Tokamaks and Mirrors) operational modes.

The correlation of the dynamic effects on long- and short-time scale transport processes in materials to steady state effects should be made an integral part of the test facility design study.

\section{B.2 Other Plasma Devices}

There have been other plasma devices suggested as possible radiation sources (Refs. 24,25 ) for the materials program. Some of these ideas are listed in Table VIII and Fig. 3. However, with the possible exception of the small 2X-II idea, very limited experimental data is available that relate to these concepts. The experiments and experience with the devices that may relate to the fundamentals of the concepts are preliminary in nature and 
limited in information on which to base trends for scaling into larger sys tems .

The feasibility of translating a small 2X-II mirror device into a test facility is directly dependent on the progress being made in the mirror confinement program. The demonstration of scientific feasibility will involve large scale (dimension and power-level) experiments at which point the device would be more appropriately designed into the FERF program (Refs. 26, 27). Even with the possible advantages of designing a scaleddown version of the concept, the development program is long-term and would not be made available for near-term ( 28 years) needs of the surface and bulk radiation programs.

Converting laser-plasma and E-beam plasma concepts into radiation sources must necessarily involve some magnetic confinement technigue of either the linear theta-pinch or the mirror type systems. Therefore, the progress in the confinement program would relate to the feasibility of these ideas.

The effective transport of energy to the plasma ions from either the E-beam or laser beam depends on the electron-ion coupling. The preliminary experiments have the purpose of establishing the efficiency of the beamion energy transport processes. The limited experimental data is inadequate to allow meaningful extrapolations for scaling into source-size systems. Theoretical estimates have been utilized in scoping the ideas for test facilities.

There are technological problems with the main subsystems of these devices, some of which are: pulsed laser beams and E-beams, development of $50 \mathrm{~kJ}$ lasers, development of E-beam systems, and developing 200-500 kG fields for confinement. 
The current state of the art in the development program of both of these devices, places a long-term potential classification of these concepts as radiation sources.

As research progresses on these devices and scaling laws are identified and experimentally verified, the potential of transforming these concepts into a radiation test facility will be reviewed and assessed.

\section{SUMMARY STATEMENT OII THE TEST FACILITIES}

In Table IX are summarized some of the data relevant to the three concepts discussed in the preceeding sections. The source intensity and flux are the most important figures of merit in assessing the capability of a machine as a research tool in the study of surface and bulk radiation effects. The flux available to the experimenter is necessarily geometry and design dependent. In this aspect, the rotating target and jet-target systems are found to have the least margin for improving the geometry factor, since the test specimens are placed at the surface of the source. The focus device can make available positions closer to the source than the $0 \mathrm{E}$, and gain a 2 or 3 fold increase in flux as a result of the improved geometry.

A closely related capability is the accessibility of the facility to accommodate many experiments simultaneously. The index of 8 listed for the DPF device is to be considered a low value. It is expected that a preliminary design would indicate that a similar number of test specimens could be located at an off-axis position and into a much higher flux region.

A most important assessment index which cannot be quantified is the significance or quality of the experimental data obtained from each device. The upper limits in flux capability and test space would introduce corresponding limits to the types of experiments which can be performed. There 
TABLE IX. Composite Summary of Parameters of Neutron and Plasma Sources

\begin{tabular}{|c|c|c|c|c|}
\hline & \multicolumn{3}{|c|}{ Neutron Source } & \multirow{2}{*}{$\begin{array}{c}\text { Plasma Source } \\
\text { DPF } \\
\end{array}$} \\
\hline & \multicolumn{2}{|c|}{ Rotating Target } & \multirow{2}{*}{$\frac{\text { Jet-Target }}{\text { Conceptual }}$} & \\
\hline & $\begin{array}{l}\text { Current } \\
\text { Operating Parameters }\end{array}$ & $\begin{array}{c}\text { Proposed } \\
\text { Scaled Parameters }\end{array}$ & & $\begin{array}{l}\text { Scoping Potential } \\
\text { Parameter }\end{array}$ \\
\hline Neutron Source Intensity, $n / \mathrm{sec}$ & $2 \times 10^{12}$ & $4 \times 10^{13}$ & $8 \times 10^{14}$ & $5 \times 10^{15}$ to $1.1 \times 10^{16}$ \\
\hline $\begin{array}{l}\text { Small Sample Distance from } \\
\text { Target, } \mathrm{cm}\end{array}$ & 0.4 & 0.4 & 0.7 & \\
\hline Geometry Factor & 2 & 2 & 8 & OE $700 \mathrm{~cm}^{2}$ \\
\hline Flux at Sample, $\mathrm{n} / \mathrm{cm}^{2}-\mathrm{sec}$ & $1 \times 10^{12}$ & $2 \times 10^{13}$ & $10^{14}$ & $7 \times 10^{12}$ to $1.5 \times 10^{13}$ \\
\hline $\begin{array}{l}\text { Accessibility, Number of } \\
\text { Experiments }\end{array}$ & 1 & 1 & 4 & 8 \\
\hline Estimated Total System Power, MW & & 0.3 & 2 & 10 \\
\hline \multirow[t]{2}{*}{ Estimated Flux at Sample, $\mathrm{n} / \mathrm{cm}^{2}-\mathrm{sec}$} & & $1 \times 10^{13}$ & $<10^{14}$ & $\begin{array}{l}7 \times 10^{12} \text { to } 1.5 \times 10^{13} \\
\left(2 \times 10^{13}\right)\left(4.5 \times 10^{13}\right)\end{array}$ \\
\hline & & & & $w^{3 / 2} \quad w^{2}$ \\
\hline
\end{tabular}


are experiments that require: minimum fluences in the range of $>10^{20} \mathrm{n} / \mathrm{cm}^{2}$, specific radiation fields, large-size test specimens, and insitu testing under heatload conditions, etc. These considerations would completely compromise the above figures of merit relating to cost.

In sumary, after a first phase level of design has been completed, the merits of a concept must be based in part on the following considerations:

(a) the level of source intensity actually available to the investigator;

(b) the capability and flexibility of the source concept to accommodate a range of experimental needs;

(c) the number of experiments which can be performed simultaneously in order to provide a broad base of support for the total facility;

(d) the economics of the research and development necessary to establish the feasibility of a concept;

(e) the experimental data output from the facility is of the quality output needed to make significant advances in understanding radiation interaction with materials; and

(f) the capital costs to build the facility, and the operating costs per experiment.

\section{RECOMMENDATIONS}

\section{A. Surface Radiation Studies}

There has recently been an increasing concern among plasma physicists that the successful operation of the fusion devices to test the scientific feasibility of plasma confinement, presently being designed or to be designed in the next few years, will depend on the control of impurities resulting 
from plasma radiation and wall surface interaction (Refs. 2-12). The impurities have the effect of increasing the radiation losses of the plasma and of introducing instabilities which enhances the diffusion of the impurities into the plasma and compromises the confinement. These impurity effects are found to be strongly species dependent. It is therefore important to correlate the mechanisms, energy spectra, and types of surface impurities with the type of radiation fields in both energy and intensity. This dependence on the quality of the impurity as a function of the incident complex radiation field of a plasma, introduces a need for developing test facilities based on a plasma source concept. The plasma problem will be of central interest in the near-term (5-8 years) plasma physics and confinement program. The successful completion of the goals and objectives outlined in the CTR confinement program as presented in Figure 3 will strongly depend on the understanding of the plasma-wall interaction and the consequences.

The program of experiments outlined by the CTR Surface Science investigators (see Table VIII) is central to the investigation of these problems. In addition to the experiments utilizing currently available or planned test facilities, the Surface Science program identifies the need for experiments with total radiation fields more characteristic of a thermo-nuclear plasma to be started in 1977 to 1978 . The purpose is to study the synergetic effects of MeV neutrons, particles, bremsstrahling, soft $X$-rays and synchrotron radiation.

Therefore, it is recommended that an effort be initiated to studiy the feasibility and conceptual design of a plasma radiation test facility in order to meet the needs outlined by the Surface Radiation program and other similarly oriented programs at the CTR laboratories. 
The plasma radiation test facility is to simulate as closely as possible a thermonuclear plasma. It would complement the facilities such as the LLL current neutron source RT-I and the proposed RT-II, ion and particle accelerators, and photon sources and eventually the proposed LASL Intense Neutron Source. Some of these facilities are already available and being used or planned to be used in combination as indicated in the surface program for the period of up to 21980 (Table VIII).

The surface studies will eventually have to be scaled to higher intensities of plasma radiation, and the facilities to satisfy these needs will be dependent on developments within the next ten years.

\section{B. Bulk Radiation Studies}

Although the bulk (neutron damage) radiation problem will become significant for the longer-term high-performance fusion power reactor systems, it is important that the current investigations in this category of materials problems be maintained and expanded. The fluxes and fluences of MeV neutrons required by this program are more severe than the intensity requirements of the surface studies at this time. The $(D, T)$ neutron source concepts that have thus far been suggested, namely the LLL RT-II and/or the LASL Supersonicjet target would satisfy a limited fraction of the bulk materials program. The limitations as to type of experiments and/or significance of the results of these experiments to the CTR program, are a consequence of the fluence capabilities of these machines, and just as important the limitations resulting from the small-size sample (effectively several $\mathrm{mm}$ in diameter) access capability at the position of peak flux. Eventually the study of both surface radiation and bulk radiation effects relating to the highperformance conditions of fusion power reactors, will require testing facilities on the level of FERF (Fusion Engineering Research Facilities). 
Preliminary scoping conceptual design stuaies on FERF type systems are being pursued by several CTR laboratories. Since these concepts are based on the fundamental principles that have to be established by the near-term plasma confinement experiments, the feasibility of these facilities to satisfy the needs of the bulk radiation experiments in indeed long-range (15 years).

However, in order to initiate and maintain basic materials damage study programs, it is recommended that the design effort include studying the potential optimization of the plasma device for neutron yield levels which would satisfy at least the needs of that phase of the bulk radiation program that is being planned for the LLL, RT-II type machine.

As a point of reference, a plasma focus device in the $10 \mathrm{MW}$ range (2 MJ-5 pps) has the potential of scaling to total neutron source strengths in the order of $5 \times 10^{15}$ to $10^{16} \mathrm{n} / \mathrm{sec}$ (Table IX). This is several orders of magnitude greater than the LLL, RT-II machine and potentially would result in a flux level at least as high as RT-II. An increased level of flux could be realized for small-size test specimens placed close-in to the source (geometry factor $\ll<00 \mathrm{~cm}^{2}$ ). With the central electrode designed to be part of the materials study program, then large-size samples at increased fluences would also become available for bulk radiation tests. C. Remarks on Facility Design

As discussed in the preceding sections of this report, of all the concepts proposed or suggested as plasma sources for developing into testing machines, the plasma focus is presently the only device that has operated in a predominantly thermonuclear plasisa mode. The experience and operating conditions up until now indicate that scaling the device to meet the levels of intensities and in the time-scale ( 1978 ) outlined in the Surface Radia- 
tion program may be a most feasible extrapolation from the conditions achieved with the focus devices at LASL, in the Euratom laboratories (Frascati, Culham, Julich) and the CEA Limeil Laboratory in France. The scaling of plasma and neutron source yields with capacitor bank energy will be extended to $1 \mathrm{MJ}$ by the plasma focus devices coming on-line within the next year or so. The Frascati (Euratom) schedule of the experiment is included in Fig. 3.

It appears therefore that a conceptual design study should be initiated on the plasma focus device as a radiation test facility. The plasma focus concept has the potential that with energy scaling and close-in geometry factors, the flux available for experiments would satisfy the longer term needs of both the surface and bulk radiation program.

An important first step in the effort would be to modify the LASL system, $720 \mathrm{~kJ}, 50-60 \mathrm{kV}$ plasma device, for operating in an optimum neutron production mode. The necessary modifications to effect the change from the $x$-ray production mode would require only a moderate level of effort. The neutron yield experiments can be performed at several capacitor bank energies between $120 \mathrm{~kJ}$ and $420 \mathrm{~kJ}$. This would experimentally establish the magnitude of the scaling factor between the $X$-ray and the neutron operating modes. In addition the set of experiments would also serve as a check on scaling of the neutron yield with the capacitor bank energies up to $420 \mathrm{~kJ}$ and eventually at $720 \mathrm{~kJ}$ for the focus device operating in the optimum neutron production mode.

A second and most significant set of experiments would be to guantitatively verify the scaling of neutron yields with a deuterium-tritium gas mixture. The expected $(D, T) /(D, D)$ cross-section scaling factor of $80-100$ for thermonuclear plasma modes could be tested at several capacitor bank 
energies. This set of experiments would require a more moderate effort but could still be completed within a 6-8 month period.

The above two sets of crucial experiments would be considered as prerequisites in experimentally demonstrating the potential to develop the plasma focus device into a plasma radiation test facility. Establishing these two scaling factors to a high degree of confidence at the $420 \mathrm{~kJ}$ or $720 \mathrm{~kJ}$ energy level would mean that a low risk factor exists in developing a plasma focus radiation test facility for the near-term and long-term needs of the CTR Surface and Bulk Radiation Programs.

The overall design study of the facility should include the following general areas:

(a) plasma focus physics and plasma diagnostics for studying and confirming neutron scaling laws, and reliability for reproduction;

(b) engineering layout to optimize the accessibility of the neutron and plasma source to a diverse and simultaneously executed experimental program;

(c) energy storage and transfer systems in the range of several $\mathrm{MJ}$,

(d) repetition rate of energy storage and transfer systems in the range of several pps;

(e) engineering heat-dissipation system for electrodes and energy storage;

(f) mechanical design of the plasma device and total systems components under cyclic mechanical stresses;

(g) central electrode design and materials program for extending lifetime of electrode (surface erosion and minimize impurities into plasma); 
(h) engineering the tritium and deuterium fueling and recovery system, vacuum and pumping systems;

(i) engineering safeguards for tritium environment;

(j) engineering the total remote-handling of components for assembly and disassembly of subsystems, and for experimental components ;

(k) surface and materials study and assessment of pulsed versus continuous radiation effects;

(1) capital costs and operating costs per experiment.

A continuous level of priority must also be maintained in following and assessing the technical developments of other plasma devices and neutron sources as potential test facilities. There may be additional unique ways of combining neutron sources, ion accelerators, and plasma devices into a total system that may be interesting to the Surface Science and Bulk Radiation program. 


\section{REFERENCES}

1. Developed in collaboration with M. Kaminsky (ANL); F. Clinard (LASL); R. Werner, et al. (LLL); W. Bauer (Sandia) and 0. Harling (PNL).

2. B. Coppi, H. P. Furth, M. N. Rosenbluth and R. Z. Sagdeev, "Drift Instability Due to Impurity Ions," Phys. Rev. Lett. Vol. 17, p. 377 (1966).

3. D. F. Düchs, H. P. Furth and P. H. Rutherford, "Radial Transport of Ions in Tokamaks Including Diffusing Oxygen and Carbon Impurities," Proc. Sixth European Conf. on Cont. Fusion and Plasma Physics, Moscow, USSR, Vol. I, P. 29 (July-August 1973).

4. E. P. Gorbunov, V. S. Zaverjaev and M. P. Petrov, "Behavior of Ions in the Tokamak-4 Plasma," Proc. Sixth European Conf. on Cont. Fusion and Plasma Physics, Moscow, USSR, Vol. I, p. 1 (July-August 1973).

5. F. DelMarco, "Measurement of the Impurity Level in the ATC," Bull. Am. Phys. Soc., Vol. 18, p. 1253 (1973).

6. S. Von Goeler, W. Stodiek and N. Sauthoff, "Impurities in the ST Tokamak, Ibid, p. 1254.

7. E. Meservey, N. Bretz, D. Dimock and E. Hinnov, "The Effects of Light and Heavy Impurities on a Tokamak Discharge," Ibid, p. 1254.

8. B. Coppi, "Plasma Modes Due to Impurity and Magnetically Trapped Ions," Phys. Rev. Lett. Vol. 31, p. 1443 (1973).

9. T. Kammash and D. L. Galbraith, "Impurity and Injection Energy Effects on Toroidal Reactor Dynamics," Proc. First Topical Meeting on the Technology of Controlled Nuciear Fusion," ANS, San Diego, California, p. 120 (April 16-18, 1974).

10. M. Kaminsky and S. K. Das, "Particle Emission From Solids Under $14 \mathrm{MeV}$ Neutron Impact," Proc. of Conf. on Surface Effects in Controlled Thermonuclear Fusion Devices and Reactors, Argonne, Illinois, p. 162, (January 10-12, 1974).

11. S. K. Das and M. Kaminsky, "Radiation Blistering of Structural Materials for Fusion Devices and Reactors," Proc. of Conf. on Surface Effects in Controlled Thermonuclear Fusion Devices and Reactors, Argonne, Illinois, p. 115 (January 10-12, 1974).

12. P. H. Rebut et al., "Plasma-Wall Interactions in the TFR Machine," Proc. of Conf. on Surface Effects in Controlled Themonuclear Fusion Devices and Reactors, Argonne, Illinois, p. 16 (January 10-12, 1974). 
13. Developed in collaboration with F. W. Wiffen, J. Stiegler, E. E. Bloom and J. H. DeVan (ORNL); W. V. Green (LASL); R. Werner, (LLL);

T. T. Claudson and H. Yoshikawa (HEDL); H. Wiedersich and B. R. T. Frost (ANL); R. D. Marsha11, R. E. Hesterman, J. L. Brimhall and W. C. Morgan (PNL).

14. Developed with M. Kaminsky (ANL). Information and coordinating needs and facility requirements were obtained from 0 . Harling (PNL); W. Bauer (Sandia); F. Clinard (LASL); R. A. Van Konynenberg and J. Mitchell (LLL).

15. R. Booth and H. H. Barschal1, "Tritium Target for Intense Neutron Source," Nuclear Inst. and Meth. Vol. 99, pp. 1-4 (1972).

16. M. C. Cline and C. R. Emigh, "An Intense Neutron Source Facility Using a Supersonic Jet Target," Proc. First ANS Topical Meeting on the Technology of Controlled Nuclear Fusion, San Diego, Calif.. p. 313 (Apri1 16-18, 1974)

17. J. W. Mather, "Dense Plasma Focus," Methods of Experimental Physics, Vol. 9, Part B, p. 187, Academic Press, New York (1971).

18. C. Maisonnier, F. Pecorella, J. P. Rager, M. Samue11i, "Recent Progress in Research on Plasma Focus," Proc. Fifth European Conf. on Controlled Fusion and Plasma Physics, Grenoble, France (August 21-25, 1972).

19. A. Bernard et al., "Neutron Measurements, Thomson Scattering and Holographic Interferometry on the Focus Experiment," Proc. Second Topical Conference on Pulsed High-Beta Plasmas Max-Plank Institut Für Plasmaphysik, Garching, Germany (July 3-6, 1972).

20. P. D. Morgan, et al., "Evidence for a Broad and Uniform NeutronProducing Plasma Column in the Plasma Focus," Proc. Sixth European Conf. on Controlled Fusion and Plasma Physics, Moscow, USSR, (July 30-August 4, 1973).

21. V. S. Imshennik, N. V. Filippov, T. I. Filippova, "Similarity Theory and Increased Neutron Yield in a Plasma Focus," Nuclear Fusion Vo1. 13, p. 929 (1973).

22. L. Michel, K. H. Schönbach and H. Fischer, "Neutron Emission from a Small 1kJ Plasma Focus," Applied Physics Letters, Vol. 24, No. 2, p. 57 (January 15, 1974).

23. K. Ware and J. Mather (LASL) (private communication).

24. P. J. Persiani, "A Report on the Development of Intense Neutron Source Facilities for the CTR Technology Program," ANL/CTR-73-01 (August 1973). See also Proc. of IAEA Workship, Culham, United Kingdom, p. 305 (January 29-February 15, 1974). 
25. P. J. Persiani, "Study of the Development of Neutron and Plasma Radiation Test Facilities for the CTR Materials Program," Proc. First ANS Topical Meeting on the Technology of Controlled Nuclear Fusion, San Diego, California, p. 283 (April 16-18, 1974). See also ANL/CTR-74-01, Argonne National Laboratory (1974).

26. C. E. Taylor, "Summary of a Conceptual Design of a Mirror Reactor for a Fusion Engineering Research Facility (FERF)," Proc. First ANS Topical Meeting on the Technology of Controlled Nuclear Fusion, San Diego, California, p. 294 (April 16-18, 1974).

27. R. J. Burke, T. A. Coultas and M. Petrick, "Conceptual Design for a Theta-Pinch Fusion Engineering Research Facility (FERF), "Ibid, p. 350 . 